\title{
Simulation and Empirical Studies of the Commercial SI Engine Performance and Its Emission Levels When Running on a CNG and Hydrogen Blend
}

\author{
Rafaa Saaidia ${ }^{1,2, *}$ (D), Mohamed Ali Jemni ${ }^{1}$ and Mohamed Salah Abid ${ }^{1}$ \\ 1 Laboratory of the Electromechanical System, Department of Mechanical Engineering, National School of \\ Engineers of Sfax (ENIS), BP. 1173, 3038 Sfax, Tunisia; jemni_med_ali@yahoo.fr (M.A.J.); \\ mohamedsalah.abid@enis.rnu.tn (M.S.A.) \\ 2 Technical and Vocational Training Corporation, Department of Mechanical Engineering, Bishah Technical \\ College, BP. 688, 61922 Bishah, Province of Assir, Saudi Arabia \\ * Correspondence: rafaasaaidia@gmail.com; Tel.: +216-23209279/00966568746771
}

Received: 29 October 2017; Accepted: 14 December 2017; Published: 23 December 2017

\begin{abstract}
This article is a report on a simulation based on Computational Fluid Dynamics (CFD) and an empirical investigation of in-cylinder flow characteristics, In addition, it assesses the performance and emission levels of a commercial-spark ignited engine running on a CNG and Hydrogen blend in different ratios. The main objective was to determine the optimum hydrogen ratio that would yield the best brake torque and release the least polluting gases. The in-cylinder flow velocity and turbulence aspects were investigated during the intake stroke in order to analyze the intake flow behavior. To reach this goal, a 3D CFD code was adopted. For various engine speeds were investigated for gasoline, $\mathrm{CNG}$ and hydrogen and CNG blend (HCNG) fueled engines via external mixtures. The variation of brake torque (BT), $\mathrm{NO}_{\mathrm{X}}$ and $\mathrm{CO}$ emissions. A series of tests were conducted on the engine within the speed range of 1000 to $5000 \mathrm{rpm}$. For this purpose, a commercial Hyundai Sonata S.I engine was modified to operate with a blend of CNG and Hydrogen in different ratios. The experiments attempted to determine the optimum allowable hydrogen ratio with CNG for normal engine operation. The engine performance and the emission levels were also analyzed. At the engine speed of $4200 \mathrm{rpm}$, the results revealed that beyond a ratio of $50 \%$ of the volume of hydrogen added to CNG a backfire phenomenon appeared. Below this ratio $(0 \sim 40 \%)$ of the hydrogen volume, the CNG and Hydrogen blend seemed to be beneficial for the engine performance and for curtailing the emission level. However, at low engine speeds, the $\mathrm{NO}_{\mathrm{X}}$ concentration increased simultaneously with hydrogen content. In contrast, at high engine speeds, the $\mathrm{NO}_{\mathbf{x}}$ concentration decreased to its lowest level compared to that reached with gasoline as a running fuel. The concentration levels of $\mathrm{HC}, \mathrm{CO}_{2}$, and $\mathrm{CO}$ decreased with the increase of hydrogen percentage.
\end{abstract}

Keywords: Computational Fluid Dynamics (CFD); engine; conversion; CNG; Hydrogen; intake; turbulence

\section{Introduction}

The environmental pollution due to the exponential growth in the consumption of the fossil fuels as energy sources has become a serious challenge and threat to humanity in modern times. These fuels are in finite amounts. In addition, several experts have agreed that these fuels are exhaustible [1,2]. Indeed, in 2015 the British Petroleum (BP) global center revealed that oil reserves would last just 53 years at the current consumption rate [3]. Hence, the creation of renewable sources of energy and the development carbon-neutral energy systems have been widely recommended as strategic solutions to the threat of fuel shortage and $\mathrm{CO}_{2}$ concentration in the environment [4]. 
Among the newly introduced alternatives, hydrogen was reported to be a promising source of clean energy [5] as it can mitigate the problems of pollution and scant energy supplies which plague the environment and the economy [6-8].

In particular, hydrogen, with its immense thermal efficiency and non-carbonic nature, was selected as an ideal and a potential alternative fuel for internal combustion engines [8-10]. However, it is difficult to produce and store it in sufficient amounts at affordable prices. Due to this constraint, the majority of the current usages of hydrogen gas have been limited to its use as an additive to other fuels [11-13]. Indeed, hydrogen was recommended as a good additive to natural gas, one of the most available and cheap fossil fuels. However, [14-16] showed that the low flame speed and the high combustion temperature of natural gas reduced its thermal efficiency and increased $\mathrm{NO}_{X}$ concentrations. Hence, researchers such as Ma and Wang [11]; Verhelst and Wallner [6] and Dong et al. [17], proved that the enrichment of natural gas with hydrogen succeeded in overcoming this shortcoming.

The Advanced Power Generation Technology forum (UK) (APGFT) meeting (London 2014) emphasized the importance of using hydrogen encouraging for carbon capture and storage (CCS). The studies made by the APGTF were well appreciated by the major manufacturers especially those of the automobile. These studies presented strategies to be adapted in the medium and long terms for better and less efficient energy efficiency. The recommendations of the meeting in London in 2014 strongly pushed for the use of high content hydrogen with natural gas in combustion [8].

Unfortunately, Delorme and Rousseau [15], and Verhelst and Wallner [6] demonstrated that inside the cylinder, it is difficult to reduce the heat due to the high combustion temperature of the hydrogen enriched mixture. As a result, thermal efficiency necessarily resulted in increased $\mathrm{NO}_{\mathrm{X}}$. Moreover, Liu et al. [18], and Kawahara and Tomita [19] detected two serious problems when using hydrogen as an additive; namely, backfire and auto-ignition [8]. These were caused by the high flame speed of hydrogen and the very low combustion activation energy. To solve these problems, Lee et al. [20] opted for the use of a retarding intake valve with an opening timing and a lean mixture while Yang et al. [21] recommended injecting water into the intake manifold.

On the other hand, hydrogen as an additive to gasoline was investigated by Kahraman et al. [9]. These scholars conducted an experimental study that assessed the performance and emission of a spark ignited engine bi-fuelled with hydrogen and gasoline with a conventional ignition system. Their work showed that despite the satisfactory results at high-speed operation, hydrogen and gasoline fueling showed a great power loss at a low-speed operation.

Several works $[11,14,19,22]$ have carried out investigations on Lean-Burn for engines fuelled with hydrogen compressed natural gas (HCNGX; $x$ indicates the percentage of hydrogen) for the purpose of obtaining a low $\mathrm{NO}_{x}$ concentration. The engines were operated near the lean limit which was significantly expanded for natural gas by adding hydrogen. Besides, a small amount of hydrogen present in the blend remained insignificant as it played the role of a good anti-knock agent [14]. The effect of hydrogen concentration, in HCNG blends were discussed in many studies and results showed that the $\mathrm{CO}_{2}, \mathrm{CO}$, and $\mathrm{HC}$ concentrations were reduced by the addition of hydrogen to the CNG compared to combustion of pure CNG [10-13].

Typically, many studies treating the in-cylinder flow while analyzing the intake manifold and around the vicinity of the intake valve were carried out under the consideration of a constant filling flow and a fixed intake valve position $[23,24]$. The techniques of optical diagnostics and analysis such as Laser Doppler Anemometry (LDA), magnetic resonance velocimetry (MRV) and Particle image velocimetry (PIV) achieved a remarkable progress, but always they presented an insufficiency in the description and resolution around the intake valve. LDA techniques were applied in the experiments that using either air or a liquid as an intake fluid in the I.C engines benches $[25,26]$. Freudenhammer et al. [26] adopted the MRV technique to investigate the flow within the valve and cylinder during intake stroke for a single-cylinder optical engine. The measurements were performed based on the average flow velocity and the manifold diameter while using water as a 
working fluid. The flow showed important velocity fluctuation through the valve curtain, due to difficulty of flow passage in the valve seat. In these regions the local mass flow filling the cylinder considerably decreased, thus having a strong effect on the in-cylinder flow pattern. In spite of the considerable development in optical diagnostic techniques, the inefficiency to visualize the manifold and valve regions and the limitation in scanning the flow field with sufficient spatial resolution, restricted the detailed investigation of the flow in these areas [27]. The development of the numerical and CAD software provided researchers with great possibilities to investigate the engine behavior. The numerical simulations took into account the real operating parameters of the engine and a more detailed visualization of the flow [26-32].

As can be clearly seen from this brief review, research was focused on the effect of using hydrogen as an additive to gasoline, biogas, and natural gas. In addition, there was a particular interest in its enrichment effect on the combustion characteristics and the behavior of the converted engines. Most of the realized advancement was in idle or slow speeds. Nevertheless, the CNG-Hydrogen blend effect of the direct filling flow in-cylinder during the intake stroke on the engine volumetric efficiency was under-investigated. Furthermore, the engine output at low, medium, and high speeds did not receive much attention. Finally, most of the works on the process of hydrogen enrichment suffered from two serious shortcomings. Firstly, studies of this topic were restricted to the way of injecting hydrogen. Secondly, the techniques adopted were not commercialized due to their intricacy; i.e., their application never went beyond the laboratory scale. For these reasons, this study purported to investigate the effects of hydrogen as an enriching additive to CNG on in-cylinder flow and to determine the engine emission levels. The ultimate objectives were to find out the maximum allowable hydrogen ratio to $\mathrm{CNG}$ for an optimum engine operation and to attempt the supply of this blend to the engine by the carburetion way. It would be expected that such technique allows a flexible transition and facilitates its commercial installation.

\section{CFD Simulation}

Kacem et al. [7] as well as Hamzehloo and Aleiferis [33], Harshavardhan and Mallikarjuna [34], Rahiman et al. [28], Schmitt et al. [31] and Giannakopoulos et al. [32] recommended the numerical simulation approach as an important tool to investigate the engine in-cylinder flow. The SolidWorks Flow Simulation (SWFS) code was used in many researches treating different topics in Computational Fluid Dynamics (CFD) [7,27,35-39]. In this study, the SolidWorks Flow Simulation (SWFS) code was used to analyze the in-cylinder flow characteristics. Similar to other CFD codes, "SWFS" associates a noteworthy of functionality and accuracy with ease-of-use. This code uses Finite Volume, multi grid, Multi block time averaged Navier-Stokes equations. The methodology of the flow solver subsists in splitting the domain around each node in the grid into sub-volumes; it assures the flow continuity betwixt the nodes. The spatial discretization is obtained by following a procedure for tetrahedral interpolation scheme. As for the temporal discretization, the implicit formulation is adopted [38]. The transport equation is integrated over the control volume [38,39].

The studied model consisted of the Hyundai Sonata engine inlet system devices (intake manifold, intake valve, engine head pipe, and cylinder). One of the main advantages of this code was its ability to import and mesh the required geometry directly from the CAD software. In addition, SWFS allowed studying a wide range the heat and mass transfer phenomena for complex geometries [8].

As can be seen in Figure 1, the simulation setup comprised the designing of the model part, performing the mesh resolution, defining the fluid properties and the boundary condition before running the simulation. As we studied an internal flow, the geometry of the model part defined the computational domain limits. 


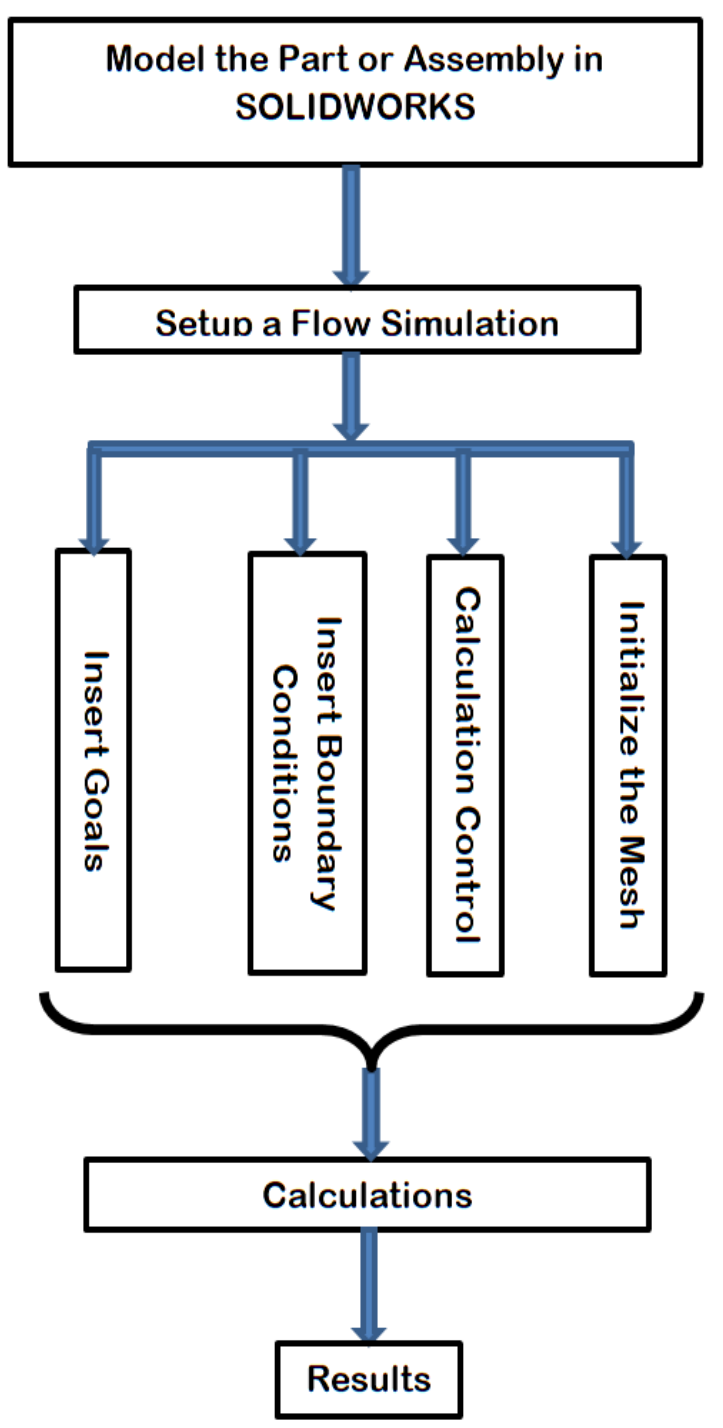

Figure 1. SolidWorks Flow Simulation (SWFS) flowchart.

\subsection{Studied Geometry}

The studied model was a Hyundai Sonata intake manifold. Table 1 illustrates the main characteristics of this engine. Due to the gazes' proprieties as shown in Tables 2 and 3, the studied engine was modified and converted into CNG bi-fueled engine. Then, it was adapted to HCNG operation. The CFD study aimed to find out the effect of the hydrogen volume fraction on the in-cylinder flow through the intake shape around the intake valves.

Table 1. Engine characteristics.

\begin{tabular}{cc}
\hline Engine Parameters & Value \\
\hline Engine type & Hyundai Sonata \\
Displacement & $1998 \mathrm{~cm}^{3}$ \\
Compression ratio & $10.4: 1$ \\
Cylinders & L4 \\
Power & 106 KW @ 6000 RPM \\
Fuel Supply System & Electronic Injection \\
Fuel & Gasoline \\
\hline
\end{tabular}


Table 2. Fuels properties.

\begin{tabular}{cccc}
\hline Characteristics & Gasoline & CNG & Hydrogen \\
\hline Chemical formula & $\mathrm{CH}_{4}$ to $\mathrm{CH}_{12}$ & Mix. Of mainly $40 \% \mathrm{C}_{3} \mathrm{H}_{8}$ and $60 \% \mathrm{C}_{4} \mathrm{H}_{10}$ & $\mathrm{H}_{2}$ \\
Molecular weight & $100-105$ & 50 & $2.016 \mathrm{~g} / \mathrm{mol}$ \\
Lower heating value $(\mathrm{MJ} / \mathrm{kg})$ & 44.45 & 47.14 & 120.21 \\
Fire point $\left({ }^{\circ} \mathrm{C}\right)$ & $230-500$ & -500 & 490 \\
Ignition limits $(\%$ of volume) & $1.0-7.6$ & $1.5-9.5$ & $4-75$ \\
Octane number & $80-95$ & $95-111.5$ & 130 \\
\hline
\end{tabular}

Table 3. Hydrogen properties.

\begin{tabular}{cc}
\hline Hydrogen Proprety & Value \\
\hline Minimum ignition energy $(\mathrm{mJ})$ & 0.02 \\
Flame temperature $\left({ }^{\circ} \mathrm{C}\right)$ & 2045 \\
Auto ignition temperature $\left({ }^{\circ} \mathrm{C}\right)$ & 585 \\
Maximum velocity of flame $(\mathrm{m} / \mathrm{s})$ & 3.46 \\
Explosion range $(\mathrm{vol} \%)$ & $13-65$ \\
Diffusion coefficient $\left(10^{-3} \mathrm{~m}^{2} / \mathrm{s}\right)$ & 0.61 \\
\hline
\end{tabular}

To perform a series of experiments, a test bench was designed and installed according to the specifications shown in Table 1. This test bench allowed to determine the behavior of the experimental engine and to extract a series of results that would be analyzed and discussed later on.

The diagram presented in Figure 2 shows the apparatus used in the experimental system consisting of an internal combustion engine, a hydraulic brake, an acquisition card, an exhaust gas analyzer, a gas/petrol switch, an emulator, a lambda analyzer, and a computer.

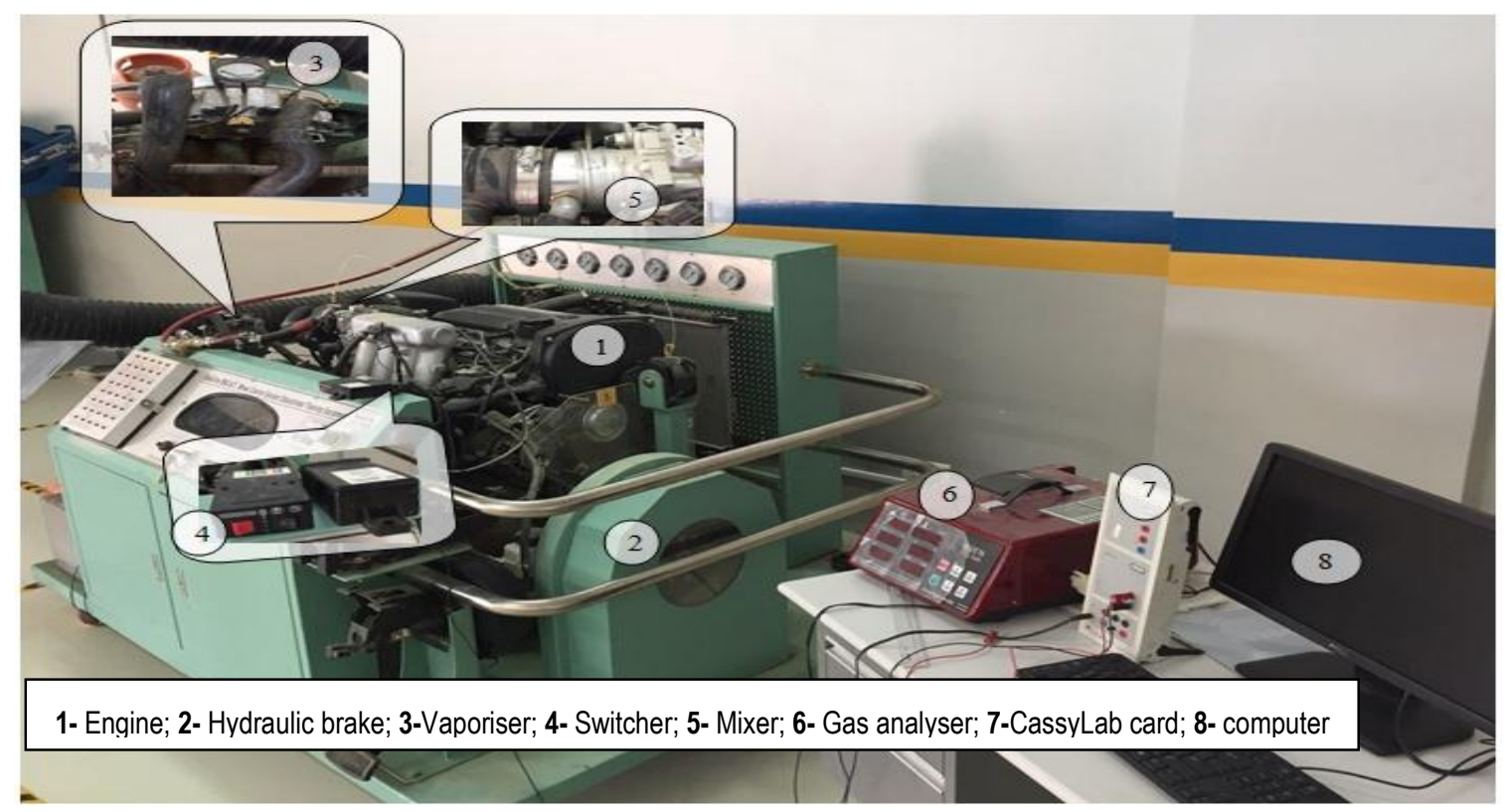

Figure 2. Bench Parts.

\subsection{Mathematical Formulation}

The CFD SWFS code was used in this study to achieve the numerical simulation. Our study was limited to the intake stroke of the engine. Because our objective was to characterize the flow along the intake manifolds and at the valve seat. The interaction with the walls and combustion process were out of the scope of the study. Therefore, the $k-\varepsilon$ model was considered more adequate 
for our purpose than other models such as $k-w$ and Random Number Generator (RNG) $k-\varepsilon$. For this reason, we adopted it. In addition, the $k-\varepsilon$ model was widely used in engine in-cylinder gaseous flow studies $[7,25,27,31]$. This model was adopted to describe the in-cylinder flow behavior for the intake manifold. To predict the turbulent flows, the Favre-averaged Navier-Stokes equations were used. The mass conservation, momentum conservation and the energy conservation are described according to the following equations:

$$
\begin{gathered}
\frac{\partial \rho}{\partial t}+\frac{\partial}{\partial x_{i}}\left(\rho u_{i}\right)=0 \\
\frac{\partial \rho}{\partial t}+\frac{\partial}{\partial x_{j}}\left(\rho u_{i} u_{j}\right)+\frac{\partial P}{\partial x_{i}}=\frac{\partial}{\partial x_{j}}\left(\tau_{i j}\right)+\tau_{i j}^{R}+S_{i} i=1,2,3 \\
\frac{\partial p H}{\partial t}+\frac{\partial}{\partial x_{i}}\left(\rho u_{i} H\right)=\frac{\partial}{\partial x_{i}}\left(u_{i}\left(\tau_{i j}+\tau_{i j}^{R}\right)+q_{i}\right)+\frac{\partial p}{\partial t}-\tau_{i j}^{R} \frac{\partial u_{i}}{\partial x_{j}}+\rho \varepsilon+S_{i} u_{i}+Q_{H} ; \\
H=h+\frac{u^{2}}{2}
\end{gathered}
$$

where " $\rho$ " is the fluid density; " $u$ " is the fluid velocity; " $h$ " is the thermal enthalpy; " $\tau_{i j}$ " is the viscous shear stress tensor; " $S_{i}$ " is a mass-distributed external force per unit mass; " $q_{i}$ " is the diffusive heat flux and " $Q_{H}$ " is a heat source. The subscripts were used to denote summation over the three coordinate directions. The energy equation is presented as follows [7,40]:

$$
\begin{gathered}
\frac{\partial \rho E}{\partial t}+\frac{\partial}{\partial x_{j}}\left(\rho u_{i}\left(E+\frac{p}{\rho}\right)\right)=\frac{\partial}{\partial x_{i}}\left(u_{i}\left(\tau_{i j}+\tau_{i j}^{R}\right)+q_{i}\right)-\tau_{i j}^{R} \frac{\partial u_{i}}{\partial x_{j}}+\rho \varepsilon+S_{i} u_{i}+Q_{H} \\
E=h+\frac{e^{2}}{2}
\end{gathered}
$$

where " $e$ " is the internal energy.

In this study since the specific heat ratio $\gamma=\mathrm{cp} / \mathrm{cr}$ was constant, the pressure can be written as follows:

$$
P=\rho r T=(\gamma-1) \rho e
$$

\subsection{Turbulence}

The description of the turbulence in the intake flow provided a solid understanding of the engine behavior. To decrease emissions and to improve the engine performance, turbulence modeling was essential for characterizing the mixing and combustion in an engine. The turbulence model focuses on the calculation of the turbulent kinetic energy $k$ and the turbulent dissipation function $\varepsilon$.

The turbulent kinetic energy and its dissipation rate are described by the following equations:

$$
\begin{gathered}
\frac{\partial \rho K}{\partial t}+\frac{\partial}{\partial x_{i}}\left(\rho u_{i} K\right)=\frac{\partial}{\partial x_{i}}\left(\frac{\partial K}{\partial x_{i}}\left(\mu+\frac{\mu_{t}}{\sigma_{k}}\right)\right)+S_{K} \\
\frac{\partial \rho \varepsilon}{\partial t}+\frac{\partial}{\partial x_{i}}\left(\rho u_{i} \varepsilon\right)=\frac{\partial}{\partial x_{i}}\left(\frac{\partial \varepsilon}{\partial x_{i}}\left(\mu+\frac{\mu_{t}}{\sigma_{\varepsilon}}\right)\right)+S_{\varepsilon} \\
S_{K}=\tau_{i j}^{R} \frac{\partial u_{i}}{\partial x_{j}}-\rho \varepsilon+\mu_{t} F_{b} \\
S_{\varepsilon}=C_{\varepsilon 1}\left(f_{1} \tau_{i j}^{R} \frac{\partial u_{i}}{\partial x_{j}}+\mu_{t} C_{b} F_{b}\right)+C_{\varepsilon 2} f_{2} \frac{\rho \varepsilon^{2}}{K}
\end{gathered}
$$

$S_{K}$ and $S_{\varepsilon}$ are the source terms;

$F_{b}$ is the turbulence generated by the buoyancy forces. 


$$
\begin{cases}C_{b}=1 & \text { if } F_{b}>1 \\ C_{b}=0 & \text { if } F_{b} \leq 1\end{cases}
$$

The empirical constants in SWFS code have the following values:

$$
C_{\varepsilon 1}=1.44, C_{\varepsilon 2}=1.92
$$

\subsection{Computational Setup}

\subsubsection{Boundary Conditions}

The boundary and initial conditions were defined in function of each running case. Some simplifications were taken for the calculation. The cylinder walls were supposed to be adiabatic walls. This study took into account only the critical cylinder $\mathrm{N}^{\circ} 4$ as in the intake stroke. The Figures 3 and 4 resume the boundaries and initial conditions setup. The top head piston surface was considered as a moving wall and its speed was considered as an output condition. The piston displacement computed in function of the following equation:

$$
V_{p}=-r \sin C A-\frac{r^{2} \sin C A \cos C A}{\sqrt{l^{2}-r^{2} \sin ^{2} C A}}
$$

The intake valves were considered as real walls with dependency translation velocity.

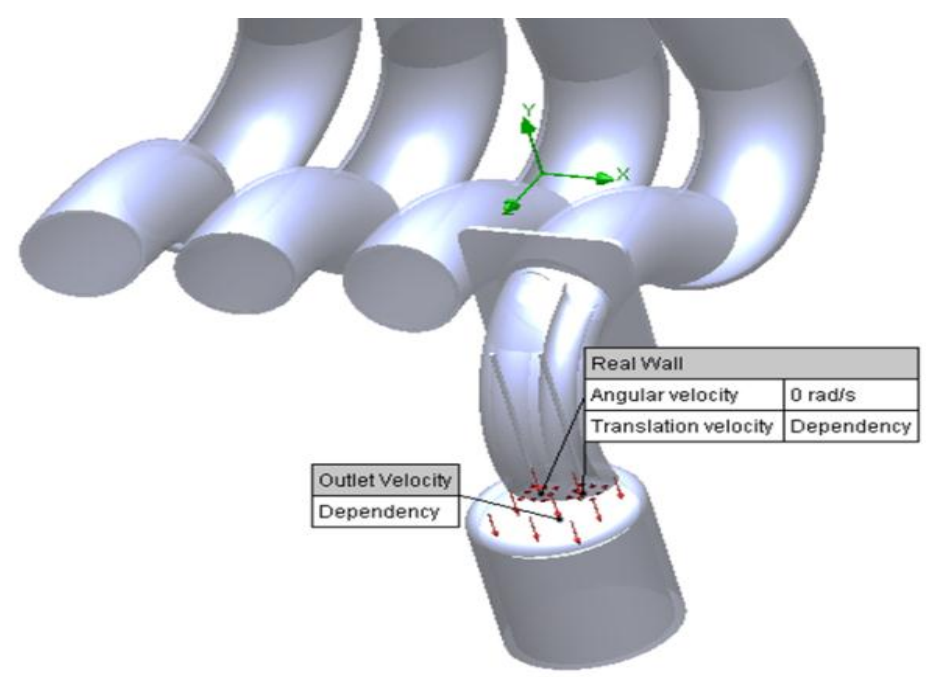

Figure 3. Boundaries conditions on piston and valves.

The pressure at the entrance of the intake manifold was maintained at the atmospheric pressure (i.e., 1.013 bar). 


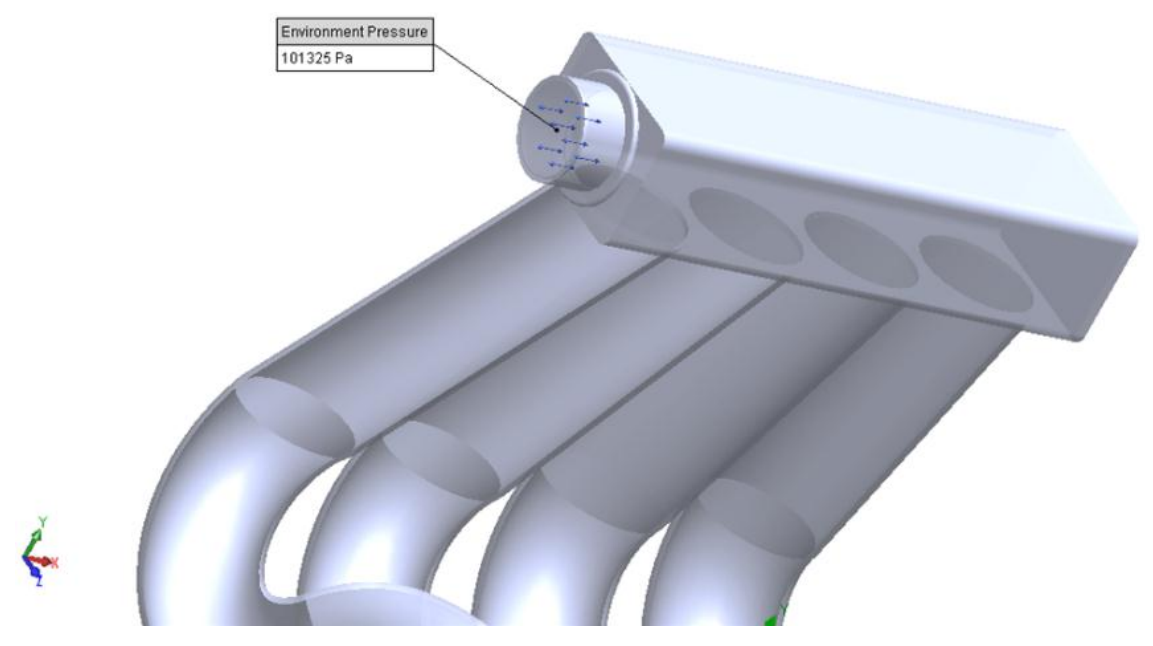

Figure 4. Boundary conditions on intake.

\subsubsection{Mesh Settings}

The SWFS code automatically generated the computational mesh in the Computational Domain function of the specified input.

First of all, the parameters governing the automatic procedure of establishing the initial computational mesh called Global Mesh had to be specified. In order to create the Global Mesh the computational domain within the coordinate system planes was divided into slices. Thus, a Basic Mesh consisting of rectangular cells was obtained. In order to better resolve the solid geometry and to attain a rigorous solution the cells of this Basic Mesh were further subdivided into smaller rectangular cells within the regions selected in function of the specified instructions.

SWFS has the capability to fit the computational mesh to the solution during the calculation. The SWFS refine the mesh cells in the high-gradient flow regions and merges the cells in the low-gradient flow regions. The mesh starts from an initial state than it is modified during the calculation based on user defined level.

The code offers seven levels of mesh refinement. The mesh refinement level specifies how many times the initial mesh cells can be split to attain the solution-adaptive refinement criteria. The solve time of a flow simulation is highly dependent on the number of cells in the computational domain. For precise results and to minimize the computation time we opted for a sufficient minimum level of mesh. Our approach consisted in simulating the pressure in the intake manifold plenum for different mesh resolutions and in comparing the numerical results with the measured ones. The increasing of the mesh resolution level engenders a higher mesh refining, which generates a larger number of cells. The mesh grid sizes for the tested refining level are summarized in the following tables.

Table 4 shows that the fluid cells size changes clearly between the different mesh resolution levels but the fluid cells contacting solids are practically the same for the 4th and 5th grid level.

Table 4. Levels mesh size.

\begin{tabular}{ccccc}
\hline Mesh Level & Level 2 & Level 3 & Level 4 & Level 5 \\
\hline Fluid cells & 3031 & 20,018 & 49,598 & 121,999 \\
Fluid cells contacting solids & 2487 & 11,123 & 47,563 & 47,684 \\
\hline
\end{tabular}

Figure 5 presents the superposition of different numerical and experimental results in function of the engine speed for different mesh levels. 


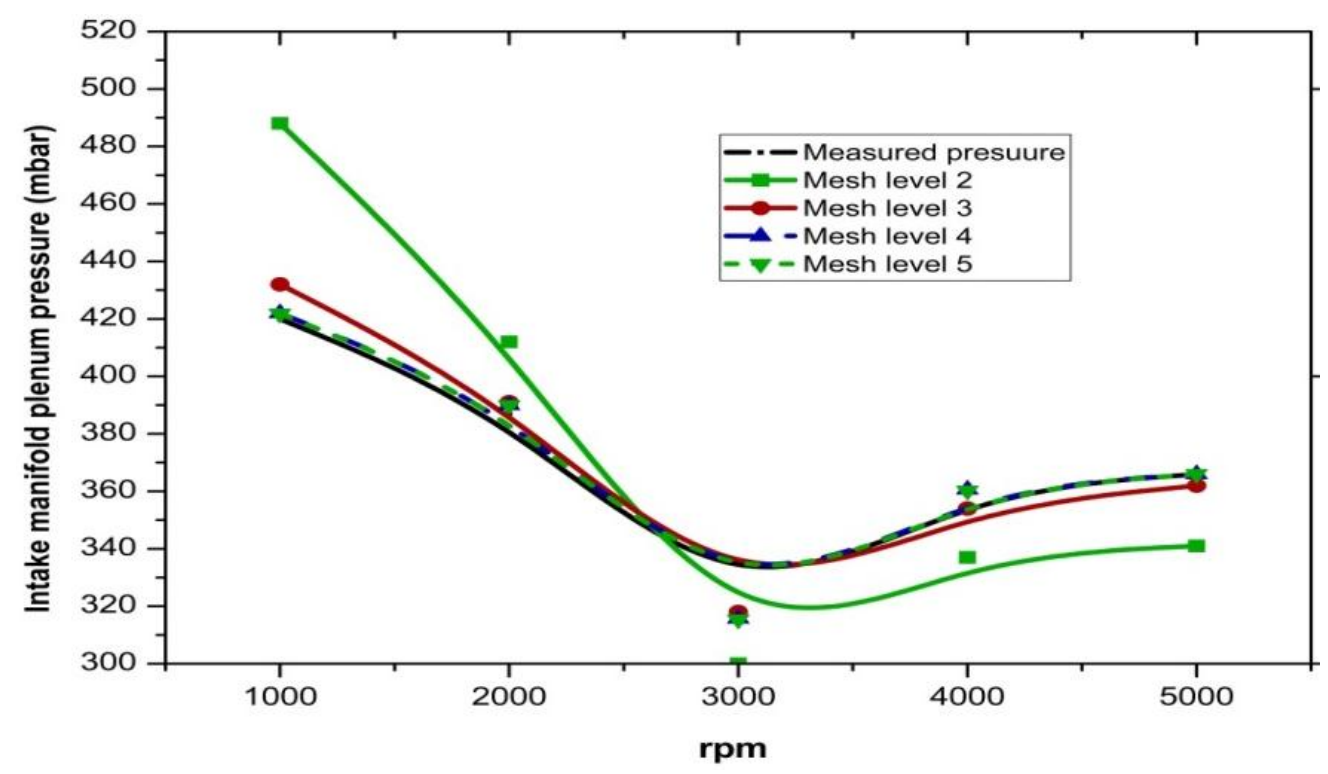

Figure 5. Computational meshing.

Figure 5 shows clearly that the meshes resolution for levels 4 and 5 yielded simulation values practically identical to the measured ones. The 4th mesh grid level was chosen in order to have valid results in the shortest computation time possible without affecting the quality of the results.

Figure 6 shows the mesh analysis resolution that was chosen to achieve the calculation.

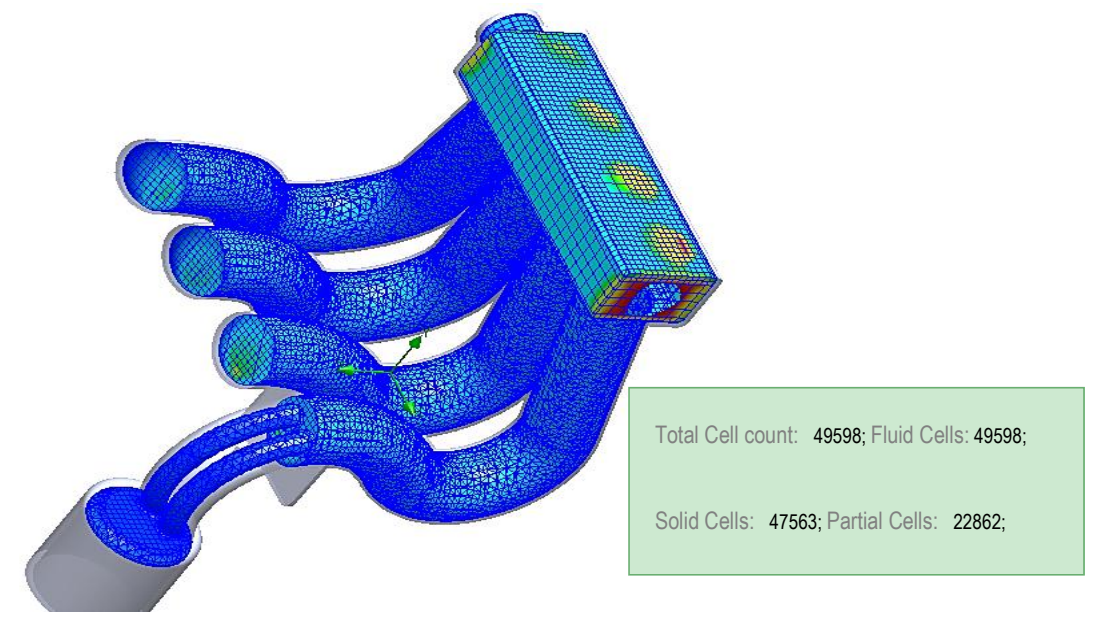

Figure 6. Computational meshing.

The follow-up of the physical parameters was recorded for three critical points goals (PG). The first point, denoted PG1, was recorded just at the intake valve. The second point, called PG2, was recorded in the combustion chamber. The third one, called PG3, was recorded in the vicinity of the intake valve.

Figure 7 below illustrates the location of the points goals. 


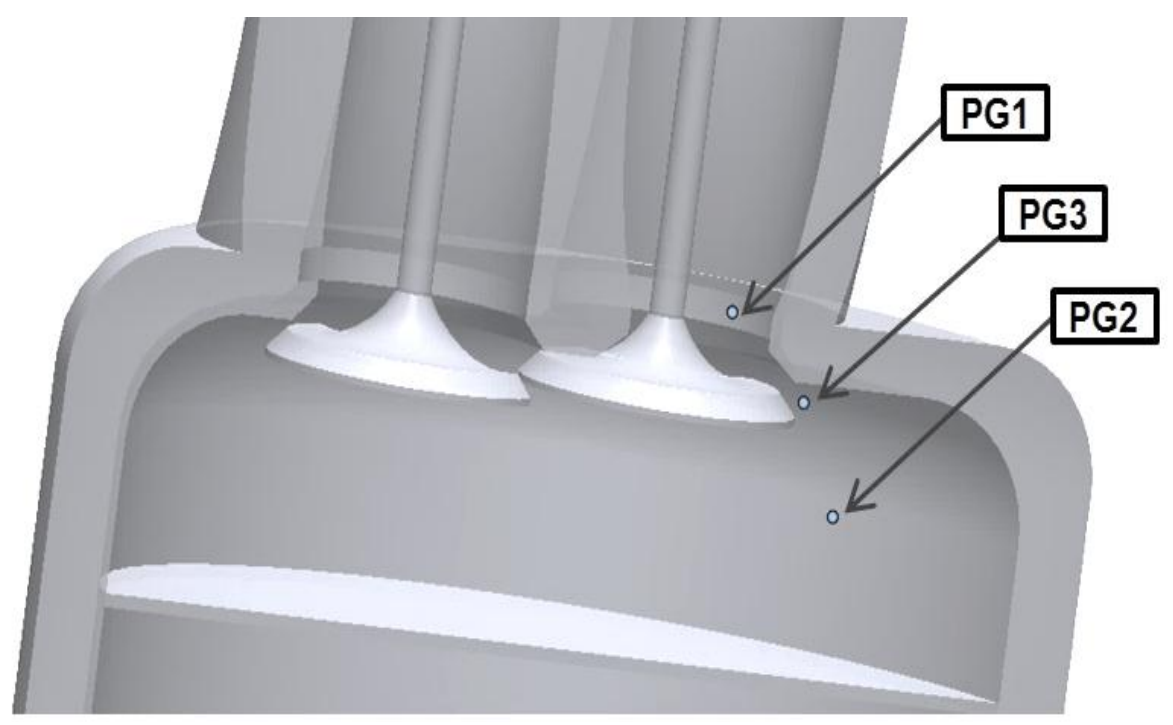

Figure 7. Computational location (Point Goals).

\section{Experimental Study}

\subsection{Experimental Apparatus}

This study adopted the commercial internal combustion engine HYUNDAI SONATA 1998cc described in Table 1. Although the fuel supply and intake system of this experimental engine were converted from gasoline to natural gas, the engine remained able to run on both types of fuels as represented in Figure 8. To adapt the engine to the new fuel, a gas mixer was mounted before the throttle valve connected to the gas flow meter and assembled in series to a vaporizer. A switch was used to shift from conventional fuel to CNG. Switching between fuels was achieved through a switch that activated a solenoid at the vaporizer. An emulator was used to play three roles. It allowed the gas flow, stopped the operation of the injectors and simultaneously, sent a signal to the electric control unit (ECU), replacing that of the oxygen sensor and providing normal operation with the new fuel. The hydrogen was compressed in a stainless tank with a pressure of about $1.2 \mathrm{MPa}$. Then, it was assembled to both the pressure controller and regulator in series of a flow meter. This equipment allowed controlling the pressure and the amount of hydrogen to be mixed with the CNG at the mixer.

The vaporizer was used for simultaneously reducing the gas fuel pressure and heating the gas as it was extremely cold. The fuel was heated by the hot water from the cooling system to avoid the malfunctioning due to the expansion of the compressed fuel in the regulator.

A CassyLab data acquisition system was connected to the Manifold Air Pressure sensor (MAP) and a computer to record the pressure profile. The analysis of the exhaust gas was made with KOEN machine. The engine was coupled with a hydraulic brake operating four pads having a surface of $410 \mathrm{~mm}^{2}$ and a friction coefficient of about 0.45 . The pads pressed against a ventilated disk with an average radius equal to $125 \mathrm{~mm}$. Furthermore, the torque value could be deduced from the pressure ensuring the full breaking of the engine.

The CNG and hydrogen were stored in two stainless steel tanks. A pressure regulator was set in series at the exit of each tank. This installation allowed controlling the outlet pressure. The fraction of hydrogen in the mixture was obtained by referring to the Dalton law for the partial pressure. The Dalton law is strictly valid for a mixture of perfect gases that connects the total pressure to the partial pressure. The partial pressure of the blend is equal to the product of the molar fraction of the total. The pressure of an ideal mixture of ideal gases is the sum of the partial pressures of each of its components. 
In order to measure the pressure, a precision pressure gauge was inserted to determine the partial pressure. The mixture forming process was carried out very slowly and carefully in order to ensure a high accuracy of the fractions in the mixture. To ensure the safety of this subsystem, a flame arrestor was introduced to prevent backfire into the flammable fuel tanks linked to a secondary pressure regulator and fire check valves. Checking for leaks before testing was essential while ventilation of the place was ensured during the experiments. All assays and measurements were performed at the low constant engine load. The gasoline running test was done at $\lambda=2$ and for the blend running at $\lambda=1.3$.

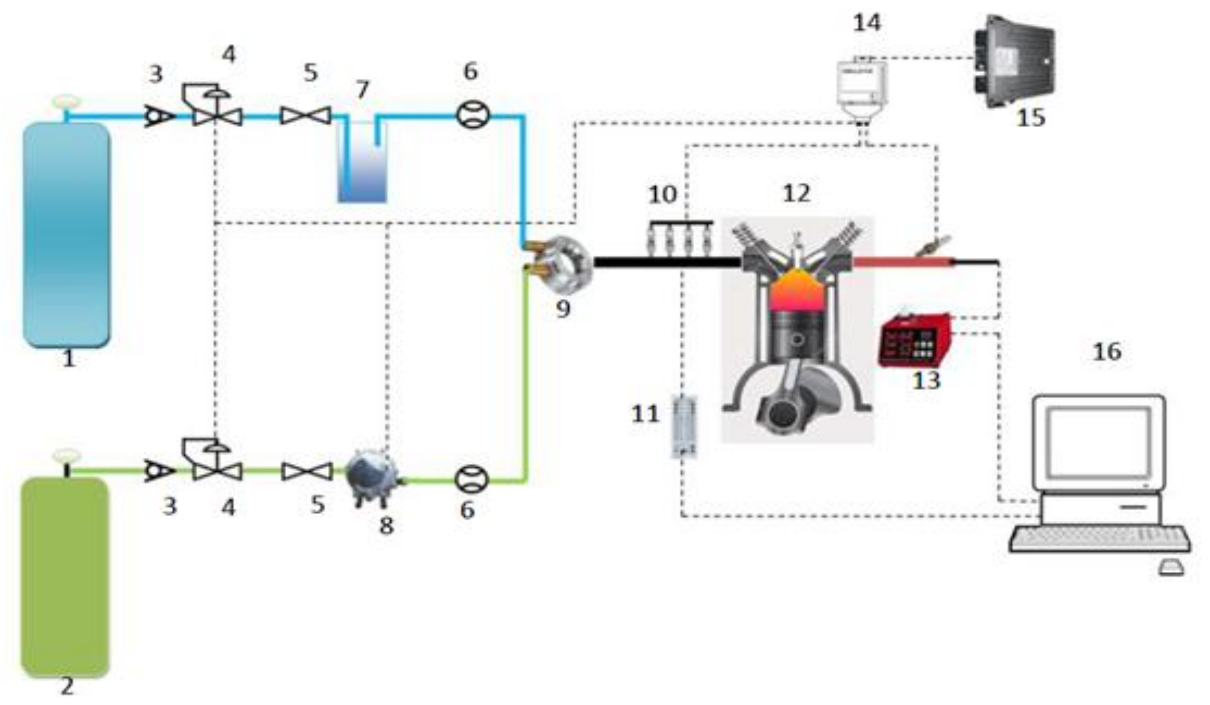

1- hydrogen tank; 2-CNG tank; 3-Check valve; 4-Pressure regulator; 5 -On/Off valve; 6-Flowmeter; 7-Flame trap; 8-vaporizer; 9-Mixer; 10 -Injectors; 11 -acquisition card (CassyLab); 12 -SI engine; 13-Exhaust gas analyzer; 14-Emulator; 15 -ECU; 16-Computer

Figure 8. Schematic diagram of bench parts.

\subsection{Estimation of Uncertainty and Error}

Measured data from experimental tests always includes degrees of uncertainty. This uncertainty may be due to several factors such as reading, the equipment accuracy and the tests methodology. For better accuracy of the tests, it is necessary to analyze random errors and uncertainty. Holman [41], Kanoglu [42], and Wheeler and Ganji [43] suggested a method estimating the accuracy based on the principle of root-mean square method. This technique was adopted in our work to estimate the accuracy. On the other hand, manufacturers of measuring instruments provide technical specifications of the capabilities of these machines (Tables 5 and 6) which will had to be taken into consideration.

Table 5. Specifications of CassyLab device.

\begin{tabular}{cc}
\hline Analog Voltage Inputs & A and B on 4-mm Safety Sockets \\
\hline Resolution: & $12 \mathrm{bits}$ \\
Measuring range: & $\pm 10 \mathrm{~V}$ \\
Measurement error: & $\pm 1 \%$ plus $0.5 \%$ of range end value \\
Input resistance: & $1 \mathrm{M} \Omega$ \\
Scanning rate: & 20,000 values $/ \mathrm{s}(=10,000$ values $/ \mathrm{s}$ per input $)$ \\
\hline
\end{tabular}


Table 6. Specifications of KOEN gas analyzer [44].

\begin{tabular}{ccc}
\hline KOEN-500 & Measure Range & Error \\
\hline Measuring gas & $\mathrm{CO}, \mathrm{HC}, \mathrm{CO}_{2}, \mathrm{O}_{2}$, Lambda AFR, $\mathrm{NO}_{\mathrm{X}}(5$ gas $)$ & - \\
$\mathrm{CO}$ & $0.00 \sim 10.0 \%$ & $0.01 \%$ \\
$\mathrm{HC}$ & $0 \sim 9999 \mathrm{ppm}$ & $1 \mathrm{ppm}$ \\
$\mathrm{CO}_{2}$ & $0.0 \sim 20.0 \%$ & $0.10 \%$ \\
$\mathrm{O}_{2}$ & $0.00 \sim 25.00 \%$ & $0.01 \%$ \\
$\lambda$ & $0 \sim 2.000$ & 0.001 \\
$\mathrm{AFR}$ & $0.0 \sim 99.0$ & 0.1 \\
$\mathrm{NO}$ & $0 \sim 5000 \mathrm{ppm}$ & $1 \mathrm{ppm}$ \\
\hline
\end{tabular}

\section{Results and Discussion}

\subsection{CFD Results and Discussion}

This section presents the numerical simulation results related to the enrichment effect of hydrogen on HCNG and on its flow behavior.

\subsubsection{Effect of Hydrogen Ratio on In-Cylinder Flow}

The intake flow velocity usually has a huge impact on the engine behavior. It is commonly known that the brake torque characteristics are mainly and closely related to the engine volumetric efficiency of the flow charge, including pumping losses. The design of intake manifold and the air-fuel in-cylinder flow characteristics alter the enhancement of fuel-air mixing, flame quality, and the exhaust emissions. The in-cylinder velocity parameter is monitored all the while by the intake stroke. The simulation was conducted while the engine was considered to run at a speed of $3500 \mathrm{rpm}$. Figures 9 and 10 illustrate the fuel blend velocity evolution according to the intake stroke time. The measurements were taken in the three critical points: before the intake valve (PG1), inside combustion chamber (PG2) and in the vicinity of the intake valve (PG3).

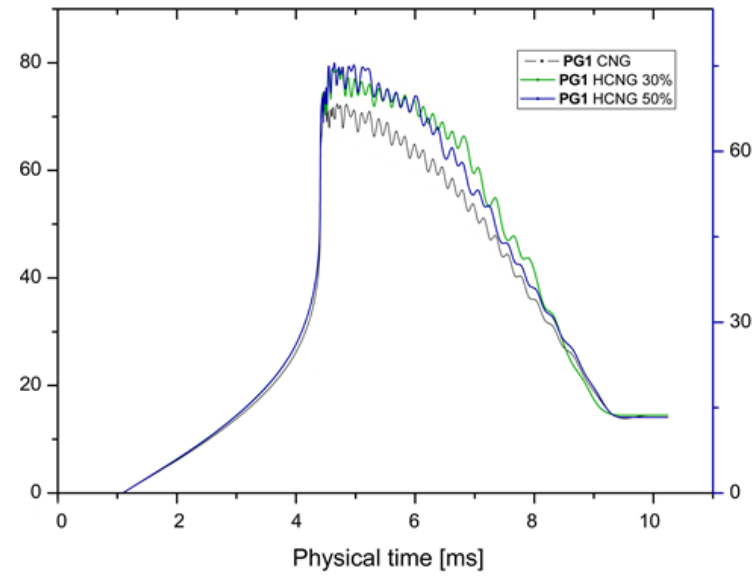

(a)

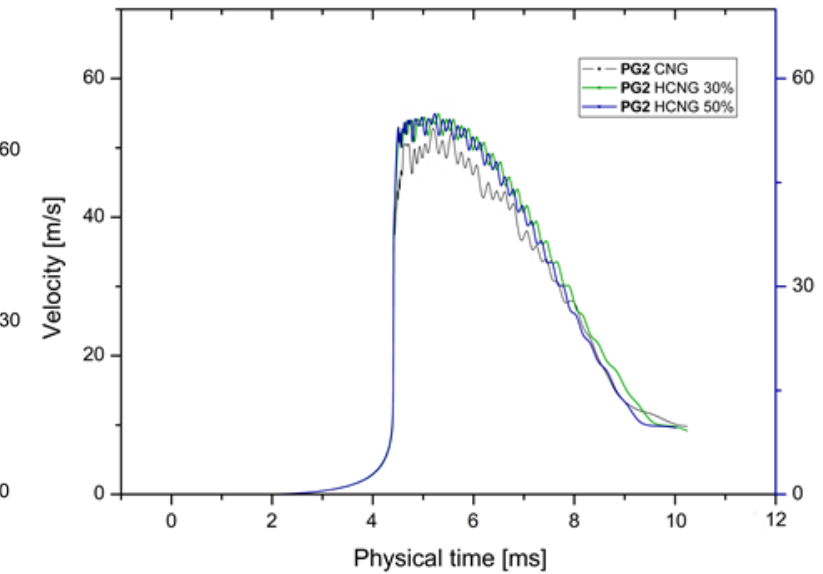

(b)

Figure 9. (a) Unsteady in-cylinder flow in the PG1 location; (b) Unsteady in-cylinder flow in the PG2 location 


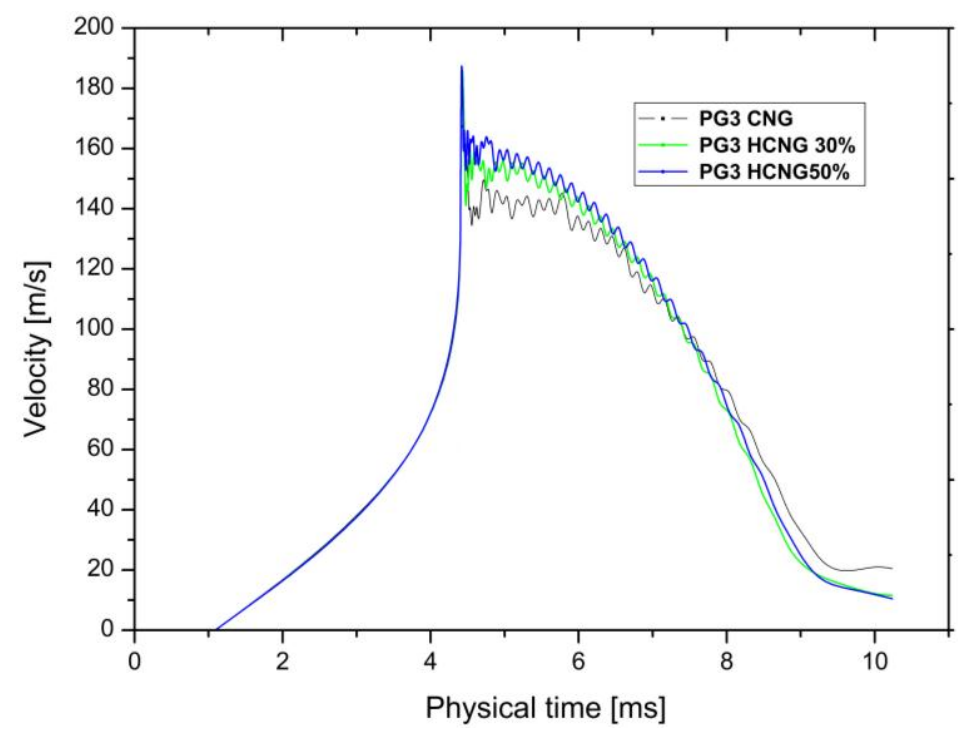

Figure 10. Unsteady in-cylinder flow in the PG3 location.

As can be seen in Figure 9, the velocity increased progressively until the intake time reached $0.0011 \mathrm{~s}$. Then, it rose sharply until the intake time reached $0.0043 \mathrm{~s}$.

Then, a degradation of the velocity was observed and the profile was substantially similar to that of the piston motion. This non-regularity of the velocity at the beginning could be practically explained by the movement of the valve caused by its opening and closing operations. During every opening a charge swiftly penetrated and generated a sharp peak. In this case thus the restriction of the passage surface it is clear that the velocity dominance is at the level of the PG3 which has reached a value of $183 \mathrm{~m} / \mathrm{s}$. Otherwise, when the passage was free, the movement depended only on the piston motion. In addition, all the curves showed fluctuations of velocity which could be explained by the sound reflection on the walls. However, they remained limited as long as the speed did not exceed that of the sound. This could be a solid proof that they are not shock waves.

Three cases of fuel nature were investigated. Figures 9 and 10 illustrate the three fuel compositions investigated in this study. It can be clearly seen that the greater the hydrogen concentration was, the higher the velocity values were recorded. Therefore, it can be induced that the cylinder filling was better and the engine volumetric efficiency improved. This improvement in the velocity was equal to $3.2 \%$. These scholars explained it by the action of the hydrogen molecules properties, which accelerated the blend particles [8].

\subsubsection{Effect of Hydrogen Ratio on Turbulent Energy}

Turbulence characterizes the irregularities, fluctuations or mixing that the fluid undergoes. In contrast to laminar flow in which the fluid travels smoothly or in regular paths, in turbulent flow, the velocity at a given point varies erratically in both magnitude and direction. For engines, more the agitation is important, the fuel mixture is more appropriate for combustion. A higher effective flame speeds and more reliable combustion are obtained for high turbulence levels. Due to the last fact the turbulence generated in the cylinder can be seen as a gain to enhance the engine behavior.

The unsteady evolutions of turbulent energy for fuels with different mixtures are represented in Figures 11 and 12 for the three selected locations of the intake system: PG1, PG2, and PG3. Through this graphic presentation, it can be clearly seen that the blend containing the highest hydrogen content generated the highest turbulence. In total agreement with $[7,45,46]$, this was explained by the hydrogen molecule acceleration and density. The peak of TE level was recorded at PG3. This can be explained by the restriction of the flow passage section through the valve lift. 


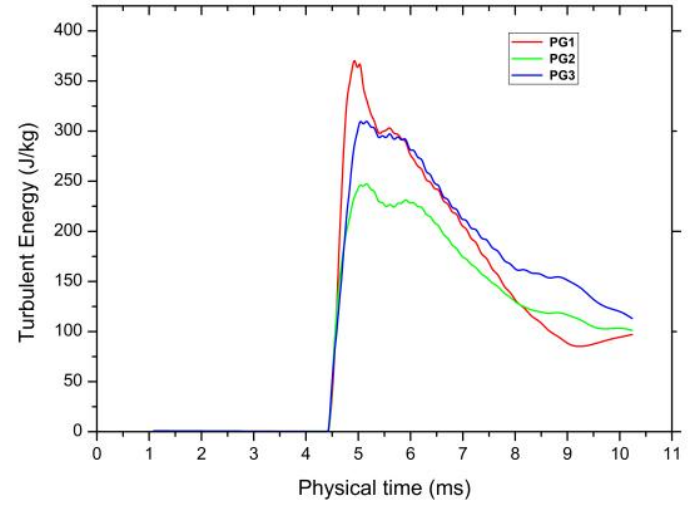

(a)

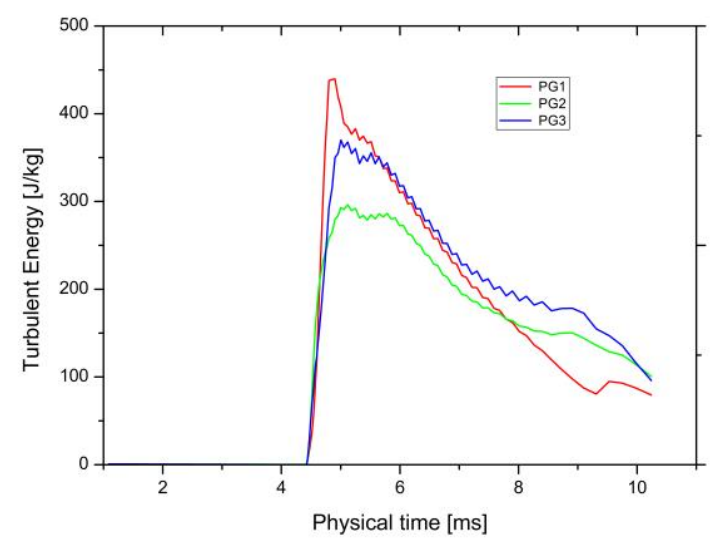

(b)

Figure 11. (a) Unsteady in-cylinder turbulent energy for pure CNG; (b) Unsteady in-cylinder turbulent energy for $\mathrm{H}_{2} \mathrm{CNG} 30$.

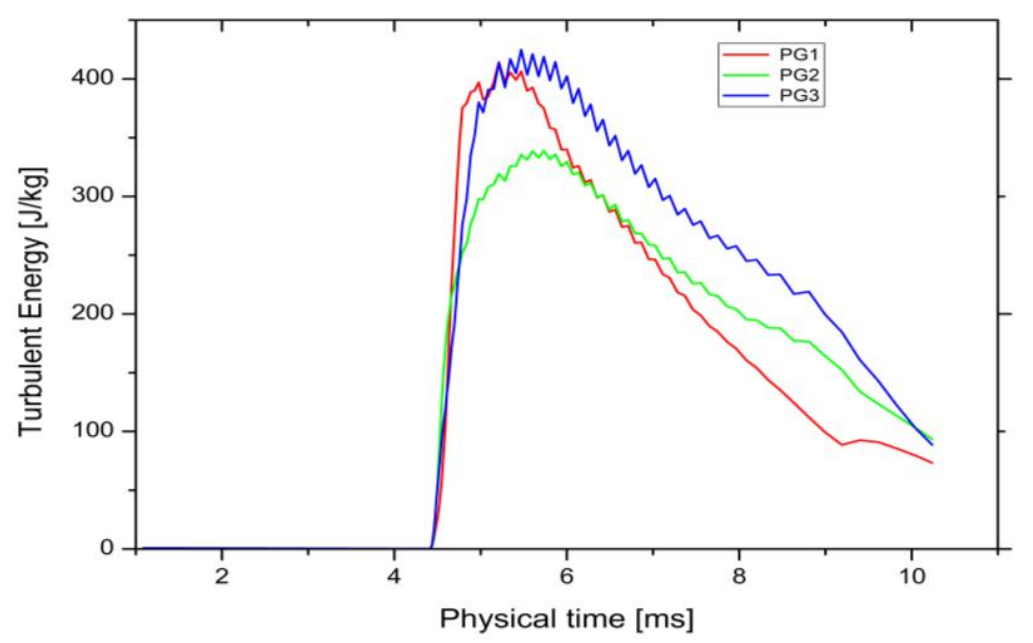

Figure 12. Unsteady in-cylinder turbulent energy for $\mathrm{H}_{2} \mathrm{CNG} 50$.

The evolution of the TE all long the intake stroke was subdivided into three fields. The first section presented a gradual evolution with a low rise at all locations levels. The second showed a relative evolution with an important gradient. The third one was at the end of the intake phase exhibiting an energy reduction.

PG2, representing the end of the intake time, showed that the fuel blend containing hydrogen received the highest agitation in the combustion chamber. This observation confirmed previous observations about the beneficial effect of the hydrogen molecules in the preparation of the air-fuel mixture [8]. Nevertheless, caution would be vital in handling Hydrogen at high concentrations in the presence of strong agitation. Indeed, such conditions may create points of auto-ignition or originate a backfire phenomenon. The mixture containing $50 \%$ of hydrogen exhibited very high levels of turbulence starting from the operating time of $0.005 \mathrm{~s}$, compared to other chosen locations. The hydrogen has low ignition energy as known and when the valves reach the ignition temperature, they ignite the mixture and generate the backfire; this fact was confirmed by the experimental application in this study. 


\subsection{Experimental Results and Discussion}

\subsubsection{Effect of Hydrogen Fraction on Performance}

The first finding of this experimental study was related to the assessment of the engine performance when operating on different fuels. Engine Brake Torque output (BT) in function of engine speed when operating on gasoline, Compressed Natural Gas (CNG) and $\mathrm{CNG} / \mathrm{H}_{2}$ fuels are measured and illustrated. Figure 13 shows the effect of Hydrogen addition to CNG on engine BT output at various engine speeds. These results showed that the BT evolution was clearly divided in three zones. The first zone corresponded to the starting engine speed (0-2000 rpm). In this zone, a significant growth gradient of torque for all kinds of fuels was observed. This growth was almost analogous with a slight advantage to the blends containing a volume of hydrogen greater than $30 \%$. The second zone corresponded to the nominal operating range; i.e., engine speeds ranging between $2000 \mathrm{rpm}$ and $3800 \mathrm{rpm}$. At this level, the BT continued to rise while showing a clear distinction depending on the fuel type. The third zone corresponded to the engine speeds above $3800 \mathrm{rpm}$. In this region, the Braque Torque curves began to have an almost constant evolution, this fact due to the kinetic energy recovered by the engine. In the first and the second zones, the gasoline domination was observed. When running on CNG, it could be observed that the BT developed by the engine running on CNG was always lower than that developed by the engine running on gasoline at above $3800 \mathrm{rpm}$. This BT failure can be due to the low energy density, which is a gaseous fuel limitation compared to the liquid fuels such as gasoline. On average, CNG produced $14 \%$ less torque than gasoline per engine BT. This process happens due to both the lower volumetric and the lower energy density of CNG in comparison with gasoline per torque stroke of the engine. In the case of liquid fuels, the fuel did not reduce the amount of air captured in the cylinder. Moreover, the engine BT was lower than its counterpart when running on gasoline over the entire engine speed range. Indeed, the slower flame speed of CNG was the main reason behind the low BT compared to gasoline. For speeds below $2000 \mathrm{rpm}$, a difference of $1.2 \mathrm{~N} \cdot \mathrm{m}$ was observed between the gasoline running torque and the CNG one. However, this value increased to an average of about $14 \mathrm{~N} \cdot \mathrm{m}$ above this speed. This difference can be explained by the fact that every operating condition is the same, while the only change is the fuel itself. Hence, some modifications in intake and ignition systems would be required.

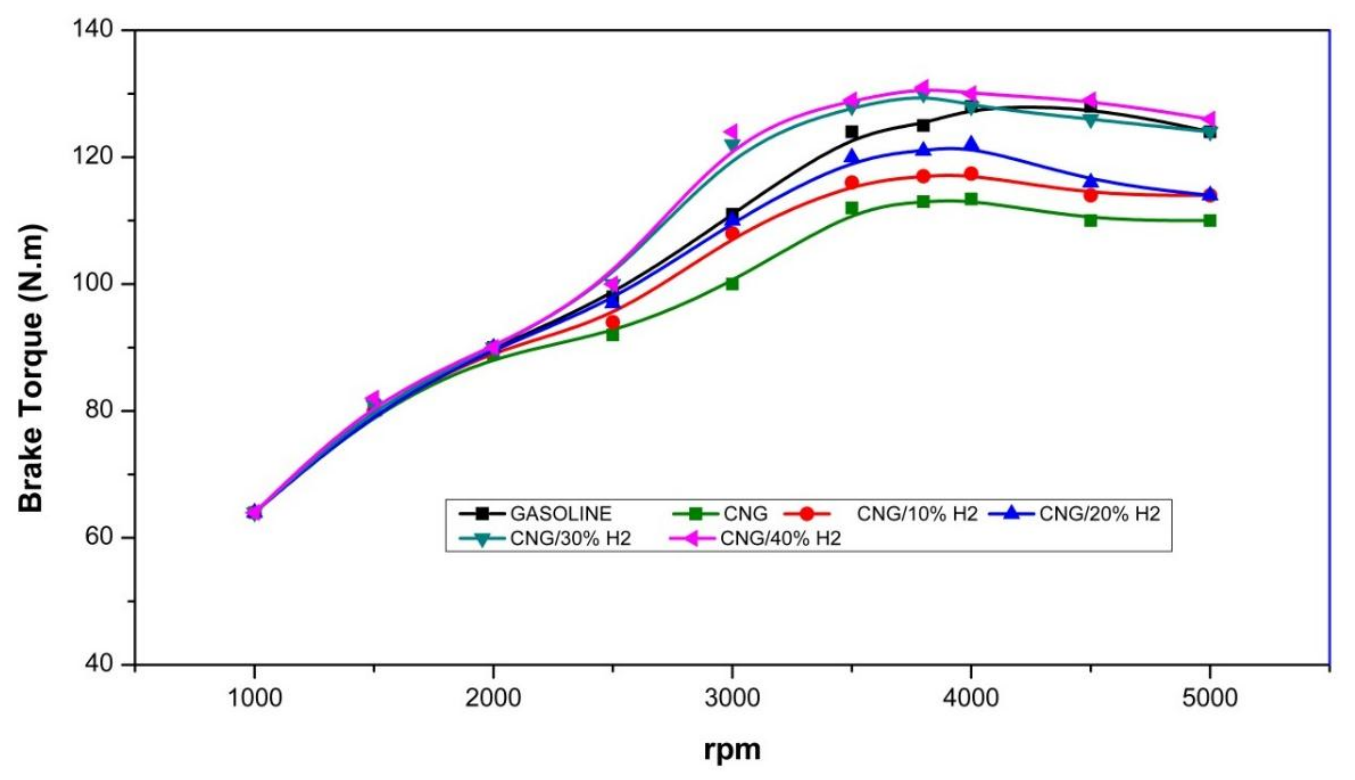

Figure 13. BT In function of engine speed for different hydrogen fraction. 
These findings confirm Akansu et al. [45] and Swain et al. [47], idea claiming that a gasoline engine converted to CNG reduces peak torque significantly. These scholars explained the phenomenon by the fact that an engine running on gasoline yields a higher torque than if it is running on CNG, particularly at higher speeds. In addition, we totally agree with Akansu et al. [45] who rightly revealed that adding hydrogen to CNG improves the engine performance. Furthermore, this work corroborates with Dong et al. [17], who argued that the addition of hydrogen to the CNG has a significant effect on the BT of the engine. These researchers specified that the BT increase was proportionate to the quantity of $\mathrm{H}_{2}$ in the blend. The higher flame speed of hydrogen hastens the combustion resulting in more fuel burning in the available time. The laminar flame speed of stoichiometric natural gas hydrogen-air mixture increases exponentially with hydrogen concentration [48].

The maximum torque was obtained at around $4300 \mathrm{rpm}$ in the case of gasoline running fuel. However, the speed yielding this torque differed when the engine was fuelled with a blend of hydrogen and CNG. When the $\mathrm{H}_{2}$ percentage in the blend was greater than $20 \%$, the maximum torque was obtained at around $3800 \mathrm{rpm}$. Hence it can be deduced that the speed corresponding to the maximum torque closely depended on the added fraction of the hydrogen to the CNG. In other words, the combustion characteristics obviously changed when the fraction of hydrogen exceeded $20 \%$. As a result, the specific consumption decreased with the blend containing more hydrogen.

The next section will assess the effect of fixing the engine rotational speed at $3500 \mathrm{rpm}$ while increasing gradually the $\mathrm{H}_{2}$ fraction in the CNG. Then we will attempt to determine the maximum amount of acceptable $\mathrm{H}_{2}$ which can yield a normal operation of the engine.

\subsubsection{Limited Use of Hydrogen Ratio via External Mixture}

The second finding concerned the determination of the maximum amount of $\mathrm{H}_{2}$ that can be added to CNG without affecting negatively the normal operation of the engine or the BT. This study decided that the optimum ratio of hydrogen was equal the amount of this fuel that caused the engine to run normally without backfiring. Such anomaly was detected through detonation sounds accompanied with a pressure pick in the intake manifold. An acquisition system was integrated into the MAP and a computer recorded the manifold pressure profile for the purpose of checking for the backfire phenomenon while the engine was running.

The engine speed was fixed at $3500 \mathrm{rpm}$. This rotational frequency was chosen because the engine yielded its maximum BT at this speed when it was fueled with hydrogen and CNG blend as shown above.

Figures 14 and 15 illustrate the pressure profile for blends made of 40 and 50\% of hydrogen. Figures 14 and 15 clearly show that at $3500 \mathrm{rpm}$, the addition of $40 \%$ or $50 \% \mathrm{H}_{2}$ to CNG allowed the engine to operate without any anomalies. In addition, Figure 15 reveals that the backfire observed at the addition of $50 \%$ of $\mathrm{H}_{2}$ had a rather limited effect since it allowed the engine to continue running. However, as can be seen in Figure $16 \mathrm{~A}, \mathrm{~B}$, ratios of $60 \%$ or $70 \%$ of $\mathrm{H}_{2}$ in the blend caused an excessive backfire phenomenon that hindered the engine operation. This could be obviously deduced from the huge number of peaks observed in the graphic presentation.

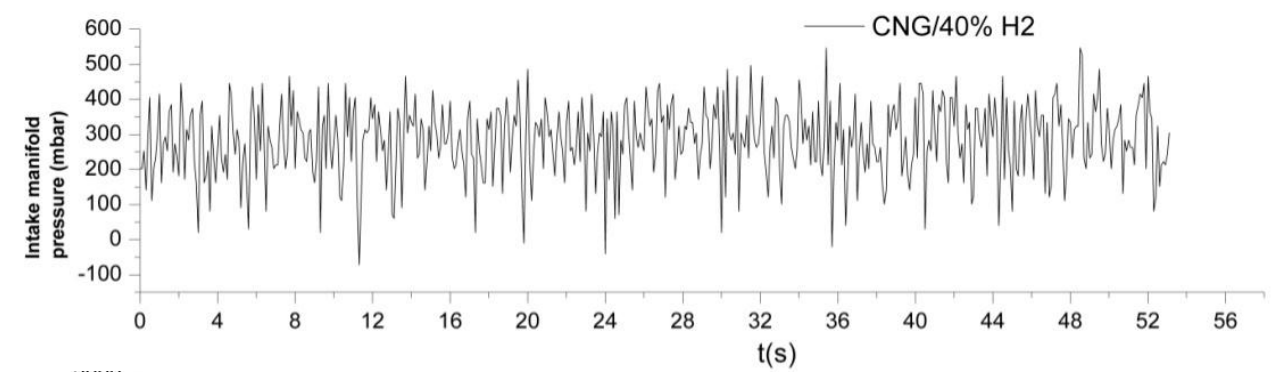

Figure 14. Intake manifold pressure profile for $\mathrm{H}_{2} \mathrm{CNG} 40$. 


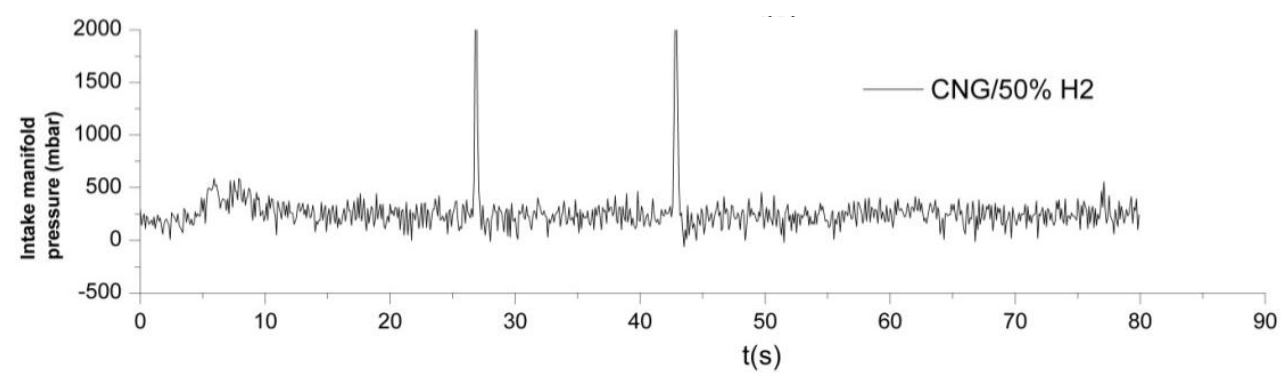

Figure 15. Intake manifold pressure profile for $\mathrm{H}_{2} \mathrm{CNG} 50$.

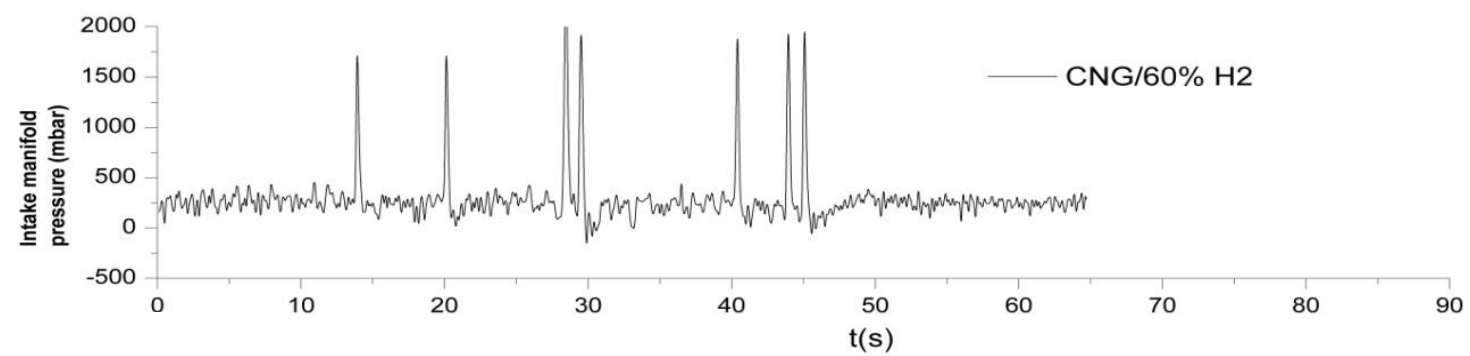

(A)

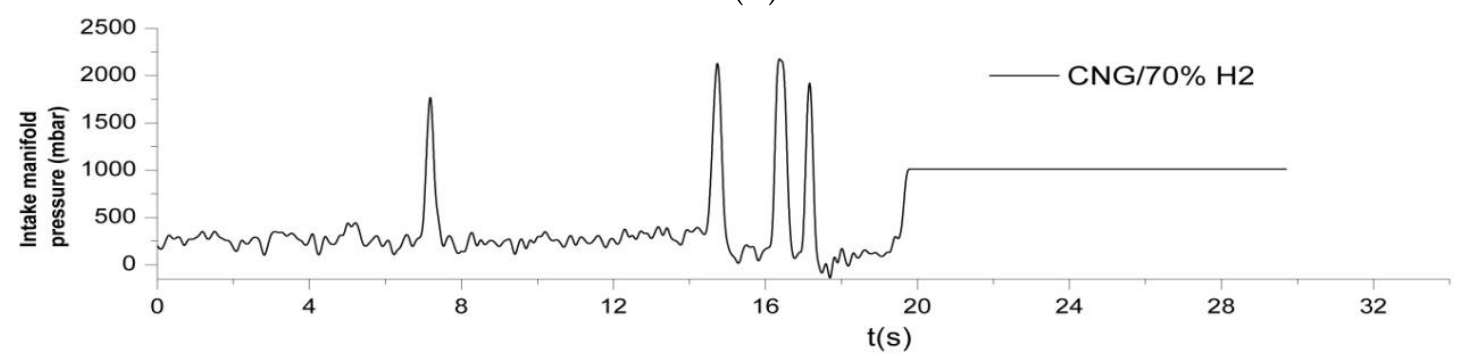

(B)

Figure 16. (A) Intake manifold pressure profile for $\mathrm{H}_{2} \mathrm{CNG60}$; (B) Intake manifold pressure profile for $\mathrm{H}_{2} \mathrm{CNG70}$.

For $60 \% \mathrm{H}_{2}$ fraction, the pressure peaks were more frequent and the abnormal operation of the engine was obvious despite the fact that the engine continued rotating.

The appearance of the backfire phenomenon could be explained by the increase in the residual fuel of the blend in the intake manifold. In addition to this hot residual burned gas in the cylinder, during the beginning of the intake stroke, the intake valves would open, heat up and ignite the combustible in the manifold due to the low ignition energy of hydrogen.

For a $70 \% \mathrm{H}_{2}$ mixture, the backfire phenomenon occurred in such rapid successions that it forced the engine to stop. This increase of backfire occurrence can be explained by the fact that the quantity of hydrogen available in the intake manifold was too excessive to handle. Therefore, it would be very safe to recommend the use of a mixture that does not exceed $40 \%$ of $\mathrm{H}_{2}$ in a converted commercial S.I engine.

Moreover, this study also recommended another possible solution for the backfire problem. Indeed, it would be possible to overcome the excessive accumulation of the unburned residues by modifying the geometry of the system or by choosing an optimal ignition time together with minimizing the valve overlap. This latter solution would extend the margin of the allowable hydrogen fraction and thus prevent the backfire. 


\subsubsection{Emission Parameters}

When an engine is running, the exhaust manifold exhales many burned and unburned gases. The exhausted gases basically contain hydrocarbons, carbon monoxide, oxides of nitrogen and sulfur, and traces of various acids, alcohols, and phenols. The most undesirable emissions are the unburned hydrocarbons $(\mathrm{HC})$, carbon monoxide (CO), and nitrogen oxides $\left(\mathrm{NO}_{\mathrm{X}}\right)$. The engine exhaust emissions are measured when operating on alternative fuels at a variety of conditions that span the practical with the normal operating ranges. In light of previous works [48-51], HC concentration increases as the mixture becomes rich due to incomplete combustion. As AFR (or $\lambda$ in this study) increases, the HC concentration decreases significantly because of the adequate oxygen amount in the mixture, which allows complete oxidation and good post-combustion oxidation of crevice gases that escape the main combustion event [52].

This study attempted to explore the level of HC concentration in function of the engine speed with a fixed excess air ratio. Figure 17 shows that at speeds below $2300 \mathrm{rpm}$, the HC concentration was significantly superior to that at speeds above $2500 \mathrm{rpm}$. This can be explained by the failure to provide the required quantity of oxygen at low speeds. In contrast, HC concentration decreased with the addition of hydrogen. Such a phenomenon can be explained by a lower methane intake. Similarly, HC concentrations from the engine operating on pure CNG were the highest. Nevertheless, the addition of $\mathrm{H}_{2}$ reduced the partial burning of $\mathrm{CNG}$ when burned at a higher velocity.

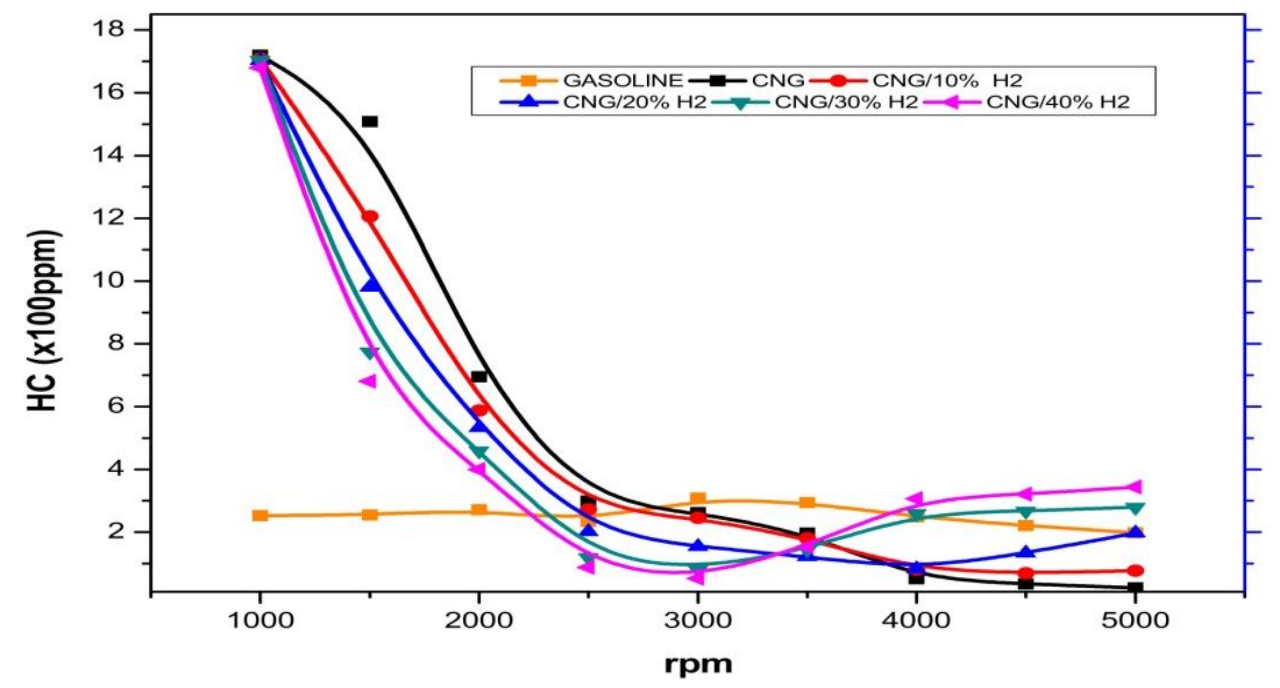

Figure 17. HC concentration in function of engine speed.

As shown in Figure 18, the CO concentration level was high and nearly constant at speeds below $2300 \mathrm{rpm}$. This high CO concentration may be due to the availability of an insufficient amount of oxygen for the combustion. However, besides the bad combustion, very likely caused by difficult ignition, slower burning velocity and even misfires would contribute to the increase of $\mathrm{CO}$ emissions. Similarly, to HC emission, it was observed that $\mathrm{CO}$ concentration decreased with the hydrogen addition. This phenomenon can be explained by the fact that carbon concentration was lower in the mixture causing the combustion to become faster and more complete due to the higher burning velocity of hydrogen. At speeds above $2500 \mathrm{rpm}$, the amount of CO decreased noticeably because the combustion of hydrogen in this range of speed would be more stable and complete due to the physical combustion properties of hydrogen mentioned above. 


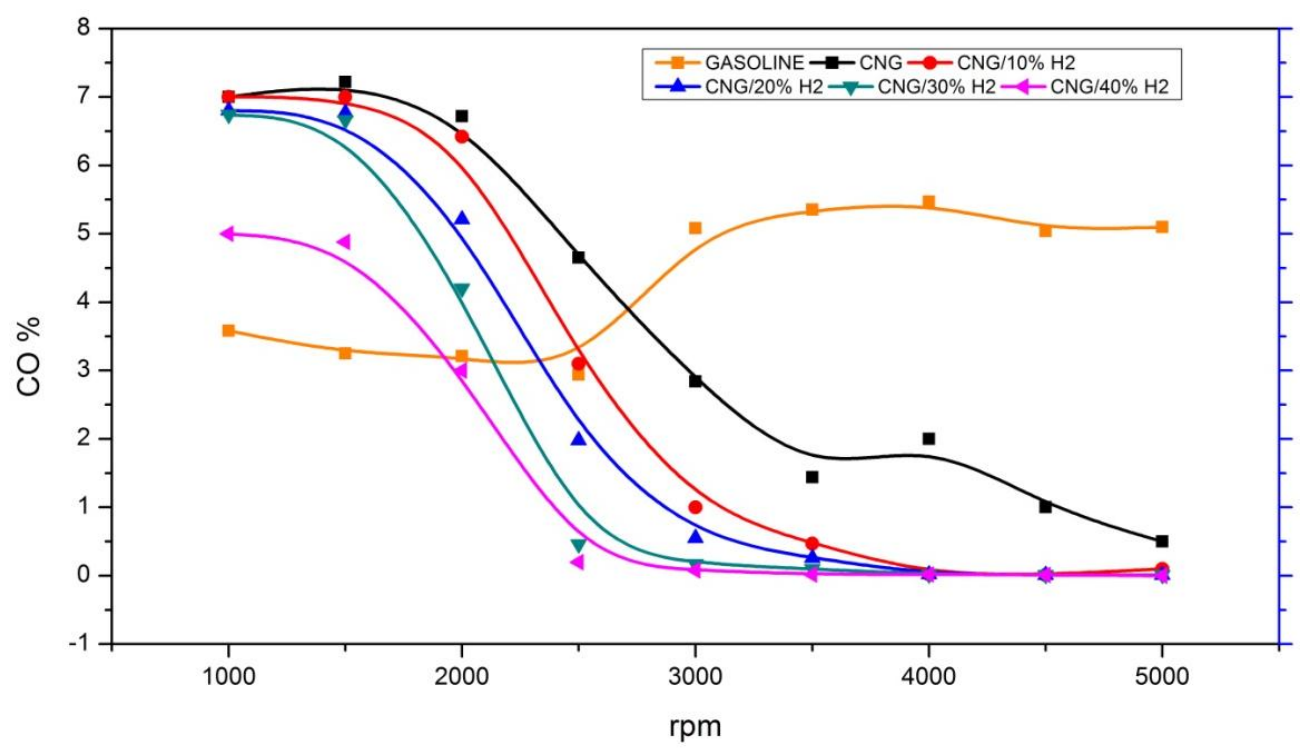

Figure 18. CO concentration in function of engine speed.

As can be seen in Figure 19, at speeds below 3000 rpm, CNG yielded the lowest $\mathrm{NO}_{X}$ concentration levels. This can be explained by CNG good knock resistance and low flame velocity. The addition of $\mathrm{H}_{2}$, however, generated a higher temperature in the cylinders, which enhanced oxidation. The combustion temperature was low due to the low load and the excessive exhaust gas existing in the cylinder and slowing the combustion.

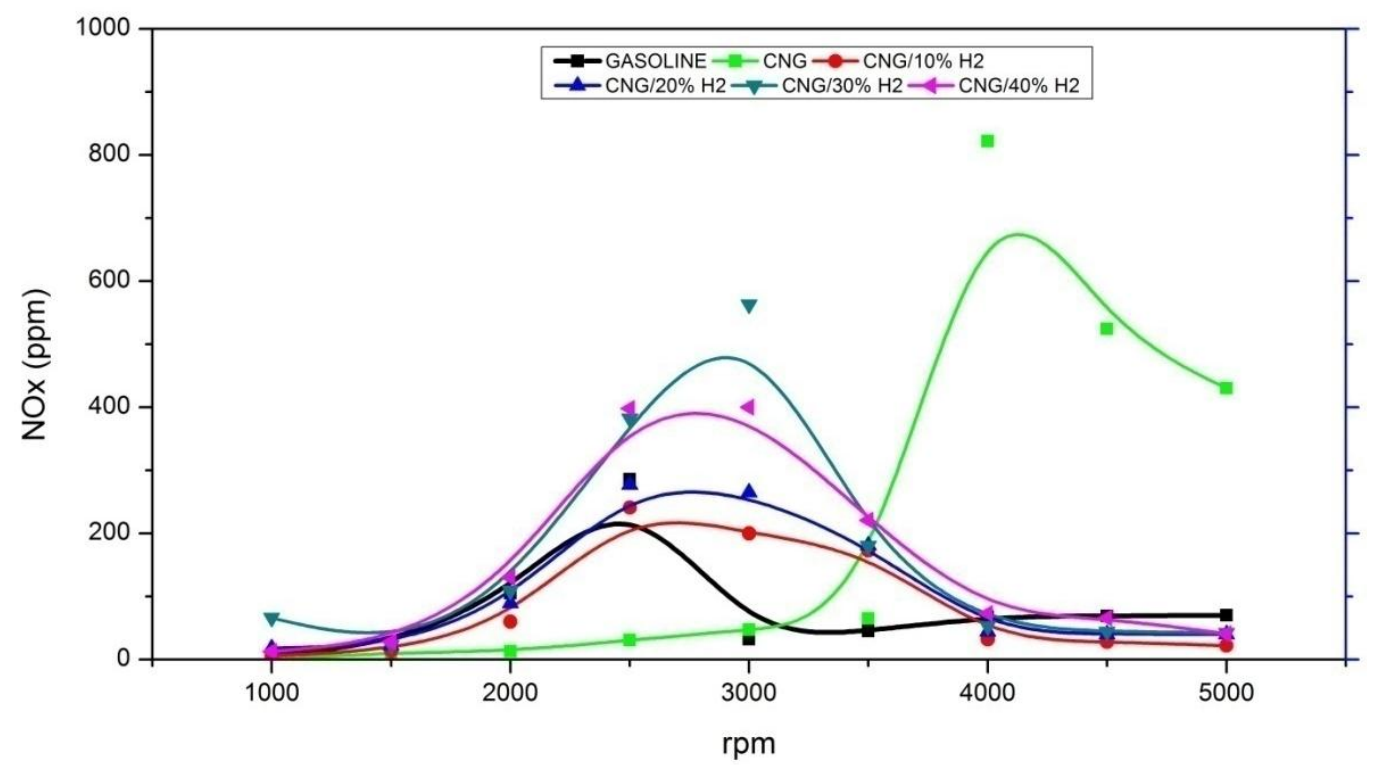

Figure 19. $\mathrm{NO}_{X}$ concentration in function of engine speed.

However, the effect of adding hydrogen to $\mathrm{CNG}$ was detrimental in terms of $\mathrm{NO}$ emission at speeds below $3500 \mathrm{rpm}$. In contrast, at the speeds above $3500 \mathrm{rpm}$, the effect of the addition of $\mathrm{H}_{2}$ was clearly positive on the combustion. This was illustrated by the inverse proportionality between the fraction of added $\mathrm{H}_{2}$ and the $\mathrm{NO}_{\mathrm{X}}$ concentration. In addition to that, good ventilation for high speed and high flame velocity of $\mathrm{H}_{2}$ would minimize the oxidation during the combustion resulting in the decline of $\mathrm{NO}_{\mathrm{X}}$ values. 


\section{Conclusions}

This work attempted a numerical simulation of in-cylinder flow in an internal combustion engine. For this purpose, the SWFS code was adopted for an initial CFD investigation. In addition, it conducted an empirical study of the optimum hydrogen ratio that can be added to HCNG fuel for a good performance and an acceptable emission rate.

The simulation revealed the following results. Firstly, Hydrogen enrichment would offer an improvement of the in-cylinder flow characteristics. Secondly, the addition of more hydrogen amounts to the CNG would improve the cylinder filling and therefore enhance the engine volumetric efficiency. Thirdly, above a certain hydrogen ratio in the blend, the agitation would gain a critical high level around the valve. This would generate an abnormal combustion that would generate backfire problems.

The empirical study resulted in the following findings. Firstly, the maximum BT produced by the engine depended on the proportion of hydrogen added to CNG. Secondly, the optimum ratio of hydrogen added to CNG to obtain a normal engine operation was equal to $40 \%$. Mixtures containing $50 \%$ hydrogen or more resulted in problems of backfire ranging between seriously disturbing the engine operation and stopping it completely.

Finally, the emission aspects resulting from every mixture proportion were determined in function of various engine speeds. Firstly, $\mathrm{NO}_{\mathrm{X}}$ concentration values increased with hydrogen proportions higher than $40 \%$.at speeds inferior to $3800 \mathrm{rpm}$. This was probably due to the high combustion temperature required by hydrogen to be totally burnt. However, at speeds above $3800 \mathrm{rpm}, \mathrm{NO}_{\mathrm{X}}$ concentration levels decreased for the mixture containing more than $40 \%$ hydrogen. Secondly, HC and $\mathrm{CO}$ concentration levels decreased with increasing hydrogen percentage. Therefore, this study ended by suggesting the use of $40 \%$ of hydrogen as an additive to CNG when an alternative to gasoline is sought. It could represent a potential solution to energetic, environmental and economic problems.

Acknowledgments: The authors would like to thank Engines and Vehicles department of Bishah Technical College (TVTC) for their help during the engine tests and financial assistance. They are also grateful for Ayadi Hajji for proofreading, correcting and improving the English of the manuscript.

Author Contributions: Rafaa Saaidia and Mohamed Ali Jemni conceived and designed the experiments; Rafaa Saaidia performed the experiments; Rafaa Saaidia and Mohamed Ali Jemni analyzed the data; Mohamed Salah Abid contributed reagents/materials/analysis tools; Rafaa Saaidia wrote the paper.

Conflicts of Interest: The authors declare no conflict of interest.

\section{References}

1. Cripp, H. Energy and the Environment. Available online: http://eco.gn.apc.org/pubs/ energyandenvironment.html (accessed on 10 August 2007).

2. Pablo-Romero, M.D.P.; De Jesús, J. Economic growth and energy consumption: The Energy-Environmental Kuznets Curve for Latin America and the Caribbean. Renew. Sustain. Energy Rev. 2016, 60, 1343-1350. [CrossRef]

3. Bp Global. BP Statistical Review of World Energy; Bp Global: London, UK, June 2017.

4. Muradov, N.Z.; Veziroglu, T.N. Green path from fossil-based to hydrogen economy: An overview of carbon-neutral technologies. Int. J. Hydrog. Energy 2008, 33, 6804-6839. [CrossRef]

5. Jean, T.R.A.P.Y. Moteur à Allumage Commandé. Available online: https:/ /www.techniques-ingenieur.fr/ base-documentaire/mecanique-th7/technologie-des-moteurs-thermiques-42165210/moteur-a-allumagecomma-nde-bm2540/ (accessed on 19 April 2010).

6. Verhelst, S.; Wallner, T. Hydrogen-fueled internal combustion engines. Prog. Energy Combust. Sci. 2009, 35, 490-527. [CrossRef]

7. Kacem, S.H.; Jemni, M.A.; Driss, Z.; Abid, M.S. The effect of H2 enrichment on in-cylinder flow behavior, engine performances and exhaust emissions: Case of LPG-hydrogen engine. Appl. Energy 2016, 179, 961-971. [CrossRef]

8. Jones, P. Induction system development for high-performance direct-injection engines. Proc. Inst. Mesh. Eng. $1966,180,42-52$. 
9. Kahraman, E.; Ozcanh, S.C.; Ozerdem, B. An experimental study on performance and emission characteristics of a hydrogen fuelled spark ignition engine. Int. J. Hydrog. Energy 2007, 32, 2066-2072. [CrossRef]

10. Bysveen, M. Engine characteristics of emissions and performance using mixtures of natural gas and hydrogen. Energy 2007, 32, 482-489. [CrossRef]

11. Ma, F.; Wang, M. Performance and emission characteristics of a turbocharged spark-ignition hydrogen-enriched compressed natural gas engine under wide open throttle operating conditions. Int. J. Hydrog. Energy 2010, 35, 12502-12509. [CrossRef]

12. Akansu, S.O.; Bayrak, M. Experimental study on a spark ignition engine fueled by $\mathrm{CH}_{4} / \mathrm{H}_{2}(70 / 30)$ and LPG. Int. J. Hydrog. Energy 2011, 36, 9260-9266. [CrossRef]

13. Ma, F.; Wang, Y.; Liu, H.; Li, Y.; Wang, J.; Zhao, S. Experimental study on thermal efficiency and emission characteristics of a lean burn hydrogen enriched natural gas engine. Int. J. Hydrog. Energy 2007, 32, 5067-5075. [CrossRef]

14. Wang, X.; Zhang, H.; Yao, B.; Lei, Y.; Sun, X.; Wang, D.; Ge, Y. Experimental study on factors affecting lean combustion limit of S.I engine fueled with compressed natural gas and hydrogen blends. Energy 2012, 38, 58-65. [CrossRef]

15. Delorme, A.; Rousseau, A. Evolution of hydrogen fueled vehicles compared to conventional vehicles from 2010 to 2045 (No. 2009-01-1008). SAE Tech. Pap. 2009. [CrossRef]

16. Huang, Z.; Liu, B.; Zeng, K.; Huang, Y.; Jiang, D.; Wang, X.; Miao, H. Experimental study on engine performance and emissions for an engine fuelled with natural gas-hydrogen mixtures. Energy Fuels 2006, 20, 2131-2136. [CrossRef]

17. Dong, C.; Zhou, Q.; Zhang, X.; Zhao, Q.; Xu, T.; Hui, S.E. Front. Experimental study on the laminar flame speed of hydrogen/natural gas/air mixtures. Chem. Eng. China 2010, 4, 417-422. [CrossRef]

18. Liu, X.; Liu, F.; Zhou, L.; Sun, B.; Schock Harold, J. Backfire prediction in a manifold injection hydrogen internal combustion engine. Int. J. Hydrog. Energy 2008, 33, 3847-3855. [CrossRef]

19. Kawahara, N.; Tomita, E. Visualization of auto-ignition and pressure wave during knocking in a hydrogen spark-ignition engine. Int. J. Hydrog. Energy 2009, 34, 3156-3163. [CrossRef]

20. Lee, K.; Huynh, T.C.; Lee, J. A study on realization of high performance without backfire in a hydrogen-fueled engine with external mixture. Int. J. Hydrog. Energy 2010, 35, 13078-13087. [CrossRef]

21. Yang, Z.; Wang, L.; Zhang, Q.; Meng, Y.; Pei, P. Research on optimum method to eliminate backfire of hydrogen internal combustion engines based on combining postponing ignition timing with water injection of intake manifold. Int. J. Hydrog. Energy 2012, 37, 12868-12878. [CrossRef]

22. Cho, H.M.; He, B.Q. Combustion and emission characteristics of a lean burn natural gas engine. Int. J. Automot. Technol. 2008, 9, 415-422. [CrossRef]

23. Heim, D.; Ghandhi, J. Investigation of swirl meter performance. Proc. Inst. Mesh. Eng. 2011, 225, 1067-1077. [CrossRef]

24. Tindal, M.; Cheung, R.; Yianneskis, M. Velocity characteristics of steady flows through engine inlet ports and cylinders. SAE Tech. Pap. 1988. [CrossRef]

25. Bicen, A.; Vafidis, C.; Whitelaw, J. Steady and unsteady airflow through the intake valve of a reciprocating engine. J. Fluids Eng. 1985, 107, 413-420. [CrossRef]

26. Freudenhammer, D.; Baum, E.; Peterson, B.; Böhm, B.; Jung, B.; Grundmann, S. Volumetric intake flow measurements of an IC engine using magnetic resonance velocimetry. Exp. Fluids 2014, 55, 1724. [CrossRef]

27. Genc, O.; Toros, S.; Timurkutluk, B. Determination of optimum ejector operating pressures for anodic recirculation in SOFC systems. Int. J. Hydrog. Energy 2017, 43, 20249-20259. [CrossRef]

28. Rahiman, A.; RK, A.R.; AD, M.S.; Ramis, M.K. CFD Analysis of Flow Field Development in a Direct Injection Diesel Engine with Different Manifolds. Am. J. Fluid Dyn. 2014, 4, 102-113.

29. Hossain, S.N.; Bari, S. Effect of different working fluids on shell and tube heat exchanger to recover heat from exhaust of an automotive diesel engine. In Proceedings of the World Renewable Energy Congress, Linköping, Sweden, 8-13 May 2011.

30. Shinde, P.A. Research and optimization of intake restrictor for Formula SAE car engine. Int. J. Sci. Res. Publ. 2014, 4, 1-5.

31. Schmitt, M.; Frouzakis, C.E.; Tomboulides, A.G.; Wright, Y.M.; Boulouchos, K. Direct numerical simulation of multiple cycles in a valve/piston assembly. Phys. Fluids 2014, 26, 035105. [CrossRef] 
32. Giannakopoulos, G.K.; Frouzakisa, C.E.; Boulouchosa, K.; Fischerb, P.F.; Tomboulides, A.G. Direct numerical simulation of the flow in the intake pipe of an internal combustion engine. Int. J. Heat Fluid Flow 2017, 68, 257-268. [CrossRef]

33. Hamzehloo, A.; Aleiferis, P.G. Large eddy simulation of highly turbulent under-expandedhydrogen and methane jets for gaseous-fuelled internal combustionengines. Int. J. Hydrog. Energy 2014, 39, 21275-21296. [CrossRef]

34. Harshavardhan, B.; Mallikarjuna, J.M. Effect of piston shape on in-cylinder flowsand air-fuel interaction in a direct injection spark ignition engine-A CFD analysis. Energy 2015, 81, 361-372. [CrossRef]

35. Amaral, C.; Brandão, C.; Sempels, É.V.; Lesage, F.J. Thermoelectric power enhancement by way of flow impedance for fixed thermal input conditions. J. Power Sources 2014, 272, 672-680. [CrossRef]

36. Driss, Z.; Mlayeh, O.; Driss, D.; Maaloul, M.; Abid, M.S. Numerical simulation and experimental validation of the turbulent flow around a small incurved Savonius wind rotor. Energy 2014, 74, 506-517. [CrossRef]

37. Bellos, E.; Tzivanidis, C.; Daniil, I.; Antonopoulos, K.A. The impact of internal longitudinal fins in parabolic trough collectors operating with gases. Energy Convers. Manag. 2017, 135, 35-54. [CrossRef]

38. Driss, Z.; Bouzgarrou, G.; Chtourou, W.; Kchaou, H.; Abid, M.S. Computational studies of the pitched blade turbines design effect on the stirred tank flow characteristics. Eur. J. Mech. B Fluids 2010, 29, 236-245. [CrossRef]

39. Driss, Z.; Abid, M.S. Use of the NaviereStokes equations to study of the flow generated by turbines impellers. Navier-Stokes Equ. Prop. Descr. Appl. 2012, 3, 51-138.

40. SolidWorks Flow Simulation; Technical Reference; DS Solidworks Corp.: Waltham, MA, USA, 2015.

41. Holman, J.P. Experimental Methods for Engineers; McGraw Hill Company: Burr Ridge, IL, USA, 2012.

42. Kanoglu, M. Uncertainty analysis of cryogenic turbine efficiency. Math. Comput. Appl. 2000, 5, 169-177.

43. Wheeler, A.J.; Ganji, A.R. Introduction to Engineering Experimentation; Prentice Hall: Upper Saddle River, NJ, USA, 1996.

44. Automotive Gas Analyser KEG-500. Available online: http://koeng.com/en/product/automotive-gasanalyzer-keg-500/ (accessed on 20 November 2017).

45. Akansu, S.O.; Dulger, Z.; Kahraman, N.; Veziroğlu, T.N. Internal combustion engines fueled by natural gas-Hydrogen mixtures. Int. J. Hydrog. Energy 2004, 29, 1527-1539. [CrossRef]

46. Park, C.; Lee, S.; Lim, G.; Choi, Y.; Kim, C. Effect of mixer type on cylinder-to-cylinder variation and performance in hydrogen-natural gas blend fuel engine. Int. J. Hydrog. Energy 2013, 38, 4809-4815. [CrossRef]

47. Swain, M.R.; Yusuf, M.J.; Dulger, Z.; Swain, M.N. The effects of hydrogen addition on natural gas engine operation. SAE Tech. Pap. 1993. [CrossRef]

48. Hoekstra, R.L.; Collier, K.; Mulligan, N.; Chew, L. Experimental study of clean burning vehicle fuel. Int. J. Hydrog. Energy 1995, 20, 737-745. [CrossRef]

49. Mariani, A.; Prati, M.V.; Unich, A.; Morrone, B. Experimental Combustion analysis of a spark ignition i. c. engine fuelled alternatively with natural gas and hydrogen-natural gas blends. Int. J. Hydrog. Energy 2013, 38, 1616-1623. [CrossRef]

50. Diéguez, P.M.; Urroz, J.C.; Marcelino-Sádaba, S.; Pérez-Ezcurdia, A.; Benito-Amurrio, M.; Sáinz, D.; Gandía, L.M. Experimental study of the performance and emission characteristics of an adapted commercial four-cylinder spark ignition engine running on hydrogen-methane mixtures. Appl. Energy 2014, 113, 1068-1076. [CrossRef]

51. Korakianitis, T.; Namasivayam, A.M.; Crookes, R.J. Natural-gas fueled spark-ignition (SI) and compression-ignition (CI) engine performance and emissions. Prog. Energy Combust. Sci. 2011, 37, 89-112. [CrossRef]

52. Deng, J.; Ma, F.; Li, S.; He, Y.; Wang, M.; Jiang, L.; Zhao, S. Experimental study on combustion and emission characteristics of a hydrogen-enriched compressed natural gas engine under idling condition. Int. J. Hydrog. Energy 2011, 36, 13150-13157. [CrossRef]

(C) 2017 by the authors. Licensee MDPI, Basel, Switzerland. This article is an open access article distributed under the terms and conditions of the Creative Commons Attribution (CC BY) license (http:/ / creativecommons.org/licenses/by/4.0/). 